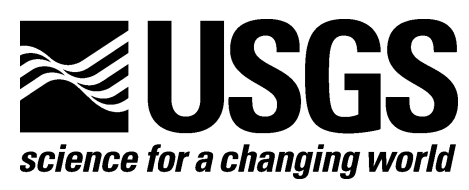

\title{
A Method for Quantitative Mapping of Thick Oil Spills Using Imaging Spectroscopy
}

By Roger N. Clark, Gregg A. Swayze, Ira Leifer, K. Eric Livo, Raymond Kokaly, Todd Hoefen, Sarah Lundeen, Michael Eastwood, Robert O. Green, Neil Pearson, Charles Sarture, lan McCubbin, Dar Roberts, Eliza Bradley, Denis Steele, Thomas Ryan, Roseanne Dominguez, and the Airborne Visible/Infrared Imaging Spectrometer (AVIRIS) Team

Open-File Report 2010-1167

U.S. Department of the Interior U.S. Geological Survey 


\section{U.S. Department of the Interior \\ KEN SALAZAR, Secretary}

\section{U.S. Geological Survey \\ Marcia K. McNutt, Director}

U.S. Geological Survey, Reston, Virginia: 2010

For product and ordering information:

World Wide Web: http://www.usgs.gov/pubprod

Telephone: 1-888-ASK-USGS

For more information on the USGS-the Federal source for science about the Earth, its natural and living resources, natural hazards, and the environment:

World Wide Web: http://www.usgs.gov

Telephone: 1-888-ASK-USGS

Suggested citation:

Clark, R.N., Swayze, G.A., Leifer, I. Livo, K.E., Kokaly, R., Hoefen, T., Lundeen, S., Eastwood, M., Green, R.O., Pearson, N., Sarture, C., McCubbin, I., Roberts, D., Bradley, E., Steele, D., Ryan, T., Dominguez, R., and the Air borne Visible/Infrared Imaging Spectrometer (AVIRIS) Team, 2010, A method for quantitative mapping of thick oil spills using imaging spectroscopy: U.S. Geological Survey Open-File Report 2010-1167, 51 p.

Any use of trade, product, or firm names is for descriptive purposes only and does not imply endorsement by the U.S. Government.

Although this report is in the public domain, permission must be secured from the individual copyright owners to reproduce any copyrighted material contained within this report. 


\section{Contents}

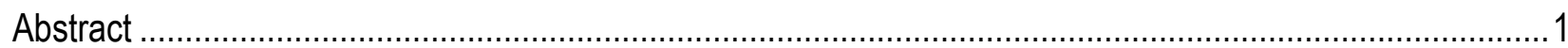

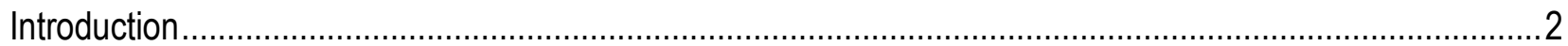

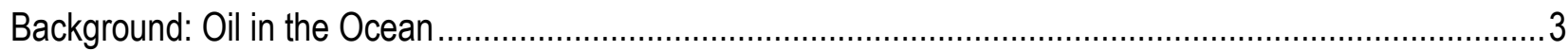

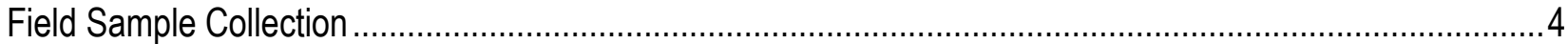

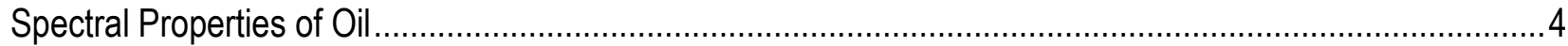

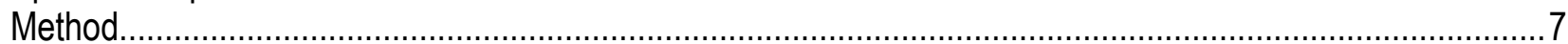

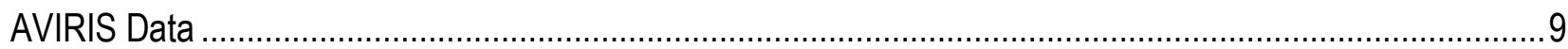

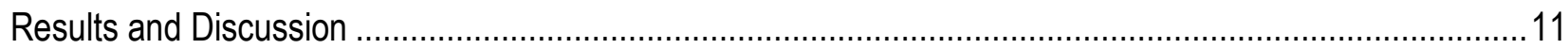

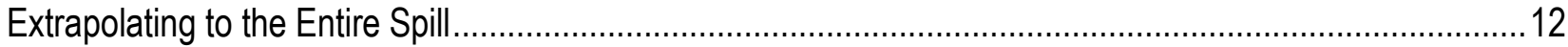

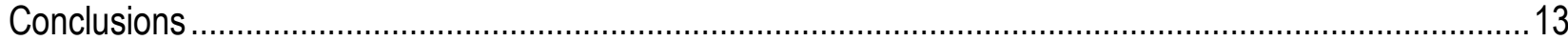

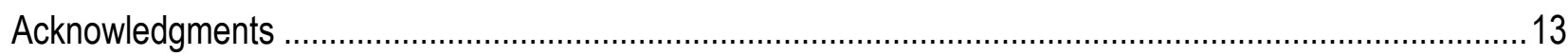

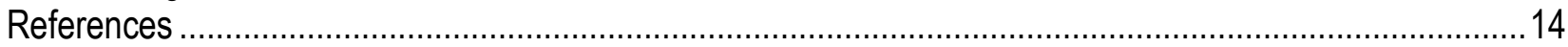

\section{Figures}

1. Image of oil emulsion from the Deepwater Horizon oil spill in the Gulf of Mexico off the Louisiana coast and major processes affecting oil spills during the initial period after the spill ...........................23

2. Laboratory spectra of oil emulsion from the Deepwater Horizon oil spill ..............................................25

3. Absorption coefficients for liquid water, decane, and benzene and for liquid water and BP crude

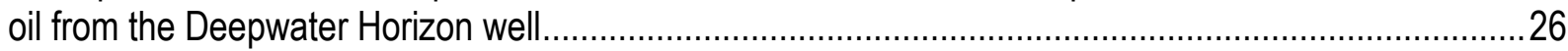

4. Illustration of how light scatters in oil on water ......................................................................28

5. Reflectance spectra of optically thick oil emulsions with high oil content and with low oil content ..........29

6. Reflectance spectra of four oil:water emulsions for a range of thicknesses (a-d) and absorbtion features of the aromatic hydrocarbon benzene in a water in oil emulsion (e).......................................31

7. Reflectance spectra of the changing spectral shape with oil-to-water ratio for the 1.2- $\mu \mathrm{m}$ and

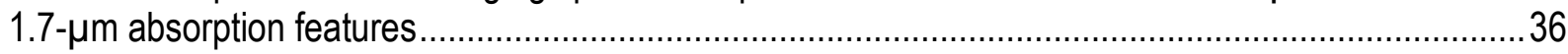

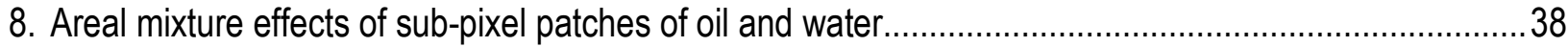

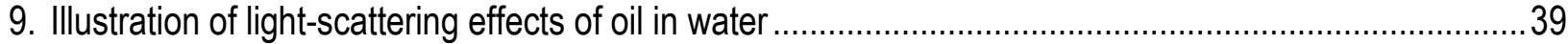

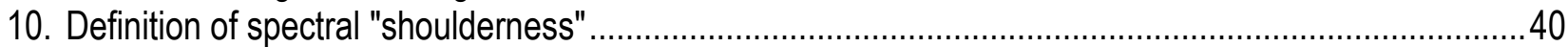

11. AVIRIS flight lines for May 17, 2010, over the Deepwater Horizon, Gulf of Mexico, oil spill...................41

12. AVIRIS visible-color composite image and example spectra .............................................................42

13. AVIRIS spectra from the May 17, 2010, flight of pixels containing no oil and of pixels containing

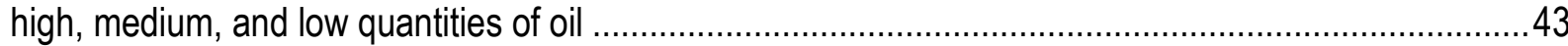

14. Mapping results from AVIRIS run 11, May 17, 2010 for oil-to-water ratio over the incident site and an area west-southwest of the incident site.............................................................................. 45

15. Mapping results for portions of AVIRIS run 11 for sub-pixel areal fraction, volume, and thickness........47

16. MODIS images showing the spectral response from the oil spill area on May 17, 2010, with AVIRIS overlay showing regions of oil and mosaic of lines $08,09,10,11$, and 14 showing oil volume..............49

\section{Tables}

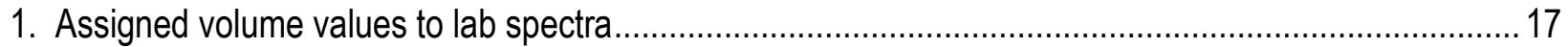

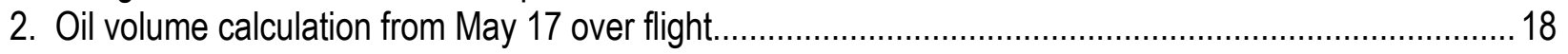




\section{A Method for Quantitative Mapping of Thick Oil Spills Using Imaging Spectroscopy}

By Roger N. Clark, ${ }^{1}$ Gregg A. Swayze, ${ }^{1}$ Ira Leifer, ${ }^{2}$ K. Eric Livo, ${ }^{1}$ Raymond Kokaly, ${ }^{1}$ Todd Hoefen, ${ }^{1}$ Sarah Lundeen, ${ }^{3}$ Michael Eastwood, ${ }^{3}$ Robert O. Green, ${ }^{3}$ Neil Pearson, ${ }^{1}$ Charles Sarture, ${ }^{3}$ lan McCubbin, ${ }^{4}$ Dar Roberts, ${ }^{5}$ Eliza Bradley, ${ }^{5}$ Denis Steele, ${ }^{6}$ Thomas Ryan, ${ }^{6}$ Roseanne Dominguez, ${ }^{7}$ and the Airborne Visible/lnfrared Imaging Spectrometer (AVIRIS) Team

\section{Abstract}

In response to the Deepwater Horizon oil spill in the Gulf of Mexico, a method of nearinfrared imaging spectroscopic analysis was developed to map the locations of thick oil floating on water. Specifically, this method can be used to derive, in each image pixel, the oil-to-water ratio in oil emulsions, the sub-pixel areal fraction, and its thicknesses and volume within the limits of light penetration into the oil (up to a few millimeters). The method uses the shape of near-infrared (NIR) absorption features and the variations in the spectral continuum due to organic compounds found in oil to identify different oil chemistries, including its weathering state and thickness. The method is insensitive to complicating conditions such as moderate aerosol scattering and reflectance level changes from other conditions, including moderate sun glint. Data for this analysis were collected by the NASA Airborne Visual Infrared Imaging Spectrometer (AVIRIS) instrument, which was flown over the oil spill on May 17, 2010. Because of the large extent of the spill, AVIRIS flight lines could cover only a portion of the spill on this relatively calm, nearly cloud-free day. Derived lower limits for oil volumes within the top few millimeters of the ocean surface directly probed with the near-infrared light detected in the AVIRIS scenes were 19,000 (conservative assumptions) to 34,000 (aggressive assumptions) barrels of oil. AVIRIS covered about 30 percent of the core spill area, which consisted of emulsion plumes and oil sheens. Areas of oil sheen but lacking oil emulsion plumes outside of the core spill were not evaluated for oil volume in this study. If the core spill areas not covered by flight lines contained similar amounts of oil and oil-water emulsions, then extrapolation to the entire core spill area defined by a MODIS (Terra) image collected on the same day indicates a minimum of 66,000 to 120,000 barrels of oil was floating on the surface. These estimates are preliminary and subject to revision pending further analysis.

Based on laboratory measurements, near-infrared (NIR) photons penetrate only a few millimeters into oil-water emulsions. As such, the oil volumes derived with this method are lower limits. Further, the detection is only of thick surface oil and does not include sheens, underwater oil, or oil that had already washed onto beaches and wetlands, oil that had been burned or evaporated as of May 17. Because NIR light penetration within emulsions is limited,

\footnotetext{
${ }^{1}$ USGS, MS 964 box 25046, Denver Federal Center, Denver, CO 80225.

${ }^{2}$ Marine Science Institute, University of California, Santa Barbara, CA 93106.

${ }^{3}$ California Institute of Technology, Jet Propulsion Laboratory, 4800 Oak Grove Dr., Pasadena, CA 91109-8099.

${ }^{4}$ Desert Research Institute, 2215 Raggio Pkwy, Reno, NV 89512.

${ }^{5}$ Department of Geography, University of California, Santa Barbara, CA, 93106.

${ }^{6}$ National Aeronautics and Space Administration (NASA) Dryden Flight Research Center, P.O. Box 273, Edwards, CA 93523-0273.

${ }^{7}$ University Affiliated Research Center, University of California, Santa Cruz/NASA Ames Research Center, Moffett Field, California, CA 94035.
} 
and having made field observations that oil emulsions sometimes exceeded 20 millimeters in thickness, we estimate that the volume of oil, including oil thicker than can be probed in the AVIRIS imagery, is possibly as high as 150,000 barrels in the AVIRIS scenes. When this value is projected to the entire spill, it gives a volume of about 500,000 barrels for thick oil remaining on the sea surface as of May 17. AVIRIS data cannot be used to confirm this higher volume, and additional field work including more in-situ measurements of oil thickness would be required to confirm this higher oil volume. Both the directly detected minimum range of oil volume, and the higher possible volume projection for oil thicker than can be probed with NIR spectroscopy imply a significantly higher total volume of oil relative to that implied by the early NOAA (National Oceanic and Atmospheric Administration) estimate of 5,000 barrels per day reported on their Web site.

\section{Introduction}

Oil remote sensing has the potential to provide emergency responders and scientists with a tool to monitor an oil spill, derive variations in chemistry and mass fluxes, and thereby develop insights into the underlying physical processes determining the fate of petroleum in the environment, whether from natural or anthropogenic sources. For example, the NRC (2003) estimates that, in a normal year, more than 55 percent of the oil in the sea is from natural sources. Quantification of these hydrocarbon fluxes largely has not been attempted, however, except for a few sites; for example, the Coal Oil Point seep field (Hornafius and others, 1999).

A rapid, quantitative, remote sensing method is needed to map the locations of thick parts of an oil spill and to assess the chemistry and amount of oil present. While simple color or multispectral imagery can show locations of oil (fig. 1a), it is difficult to assess relative thickness or volume with such data due to complex reflections and scattering of light in the oil and water, the dependency of the reflected light on scene illumination, and varying viewing geometry. In the ocean, thick oil typically forms emulsions - a mixture of tiny oil and water droplets as well as potentially air bubbles, marine organisms, and dispersants - complicating interpretation. Furthermore, oil in the marine environment tends to be highly spatially heterogeneous, with changing chemical and physical properties on a range of spatial scales, due to the complex processes affecting the fate of oil in the environment (fig. 1b).

The underlying reason for the complexity in deriving oil abundances is partly illustrated in figure 2, which shows reflectance spectra of a sample of an oil emulsion collected from the Gulf of Mexico, Deepwater Horizon 2010 spill, which contained approximately 40 percent water. In the visible part of the electromagnetic spectrum (approximately 0.4 to $0.7 \mu \mathrm{m}$ ), the color of an oil emulsion (which is significantly thicker than the wavelength of light) changes little for different thicknesses. But large changes in reflectance occur in the near infrared (NIR) (fig. 2) because the oil is less absorbing at those wavelengths. At NIR wavelengths (0.7 to 2.5 $\mu \mathrm{m})$, both the reflectance levels and the absorption features due to organic compounds in the oil vary in strength and characteristics with oil thickness, and as shown below, with the oil-to-water ratio.

In this study, we present a method to derive oil thickness and the oil:water ratio from remotely sensed spectral data of NIR spectral absorption features. This method was applied to data collected with the NASA Airborne Visual Infrared Imaging Spectrometer (AVIRIS) sensor, aboard a NASA ER-2 airplane, which flew over the Deepwater Horizon oil spill on May 17, 2010. AVIRIS measures a spectrum of the surface at each pixel from 0.35 to $2.5 \mu \mathrm{m}$ (the visible 
spectrum is: blue, $0.4 \mu \mathrm{m}$; green, $0.53 \mu \mathrm{m}$; deep red, $0.7 \mu \mathrm{m}$ ) in 224 channels (Green and others, 1998).

\section{Background: Oil in the Ocean}

Predicting the fate of oil from accidental spills as well as natural sources is a significant concern across a broad range of society, from citizens to government agencies to advocacy groups protecting delicate coastal habitat. These include not only large spills, which cause intense public and political interest, but also chronic small-scale emissions that can heavily damage the environment (Elliot, 1999). Predicting a spill's impact, and thus the best response strategy (Reed and others, 1995), requires understanding of the fate of the many oil components that have different toxicities, that is processes affecting slick chemical evolution (Riazi and AlEnzi, 1999; Labelle and Danenberger, 1997), and processes affecting its advection and dispersion.

Crude oil on the ocean undergoes physical and chemical changes due to numerous processes, shown schematically in figure $1 \mathrm{~b}$, including advection from currents and winds, wave and current compression (into windrows or narrow slicks), spreading and surface diffusion, flocculation and dissolution into the water column, evaporation, and photochemical and biological degradation (NRC, 2003). Spreading is a process whereby oil tends to maximize its surface area, and is distinct from diffusion. Both processes increase the oil-slick dimensions, while Langmuir circulations (wave compression in fig. 1b) narrow the slick (Lehr and SimecekBeatty, 2000), as do convergence zones due to current sheer, which are common in coastal waters. Both wind and currents cause slick advection and may come from different directions. Biochemical degradation occurs on a time scale of days to weeks, while the other processes mentioned can be significant on a time scale of hours or less.

Changes in oil chemical composition are important because different components have different toxicity (Labelle and Danenberger, 1997; Riazi and Al-Enzi, 1999). For example, among the n-alkanes, the more volatile compounds are more toxic (Engelhardt, 1987). Also, very low volatile organic hydrocarbons ( $\mathrm{VOH}$ ) concentrations have been shown to cause nervous system effects if inhaled (a danger to marine mammals), and gill damage to fish for VOH exposure at the parts per billion level has been documented (Spies and others, 1996).

Many of these processes depend upon sea state (Delvigne, 1987), oil-slick film thickness (ASCE, 1996), meteorology, and currents. For example, wind creates turbulence that increases evaporation, while dissolution is affected by turbulence in the water from wind stress, waves, and wave breaking. Understanding oil evolution is further complicated by the numerous components in petroleum, each with its own chemical (for example, evaporation and diffusion rates, and so forth) and physical properties (NRC, 2003).

Chemically, oil slicks originating from multiple sources can be complex in terms of the various stages of weathering. Fresh oil can become intermixed with older oil, although the two tend not to become intimately mixed except during wave action (boat wakes, wind, and so forth). While volatilization occurs on hour time scales for thin sheens and slicks (Leifer and others, 2006), evaporation proceeds much more slowly for emulsions, thick slicks, and tarballs. In addition, while volatilization is highly efficient for lighter alkanes (decane, C10 and lighter) — as well as photolysis of larger molecules into lighter volatile components - dissolution is much less efficient than volatilization. Thus, oil at the base of an emulsion or slick loses volatiles at a far slower rate. Also, volatilization from a thick emulsion becomes a two-step process; diffusion of 
the components through the oil to the surface, and then volatilization. Thus, thick emulsions will preserve their volatile components better than thin emulsions or sheens.

The fraction of oil that is volatile is important not only for reasons of toxicity, but also because many key oil physical properties (viscosity, density, diffusivity, and so forth) are altered as the oil chemical characteristics shift. Thus the physical properties, which depend on the oil's chemical composition, affect the spatial distribution of the oil under natural advective and dispersive forces.

For example, wind causes oil advection; however, once the wind passes from clear water to an oil slick, the ocean surface boundary condition changes to immobile (from mobile), and oil damping suppresses capillary waves. This shifts the wind profile such that momentum transfer to the oil at the sea surface is greatly decreased. As a result, oil slicks "bunch up" under the effect of wind. Countering this force is Fahy gravitational spreading, where the oil attempts to minimize its thickness. As a result, a thin sheen typically is observed on the upwind side of an oil slick line spreading against the advective force of the wind. The extent of this spreading of thin oil depends on the oil viscosity; thus, as oil weathers, the upcurrent sheen will spread less (but be thicker). In contrast, on the down wind side of the oil-slick line, spreading works in tandem with wind advection to create a far more extensive, thin spreading oil slick.

Although these processes suggest that oil-slick lines should disperse, in reality, slicks tend to accumulate at current sheers, which may or may not be bathymetrically induced; for example, Langmuir circulation windrows (Lehr and Simecek-Beatty, 2000) and other current convergence zones.

\section{Field Sample Collection}

Samples of natural brownish-red oil-water emulsions were collected during a May 7 , 2010, boat voyage along an east-west traverse from the Southwest Pass of the Mississippi delta out to within $7 \mathrm{~km}$ of the Deepwater Horizon incident site. Samples were collected from three emulsion slicks crossed during the voyage by dipping a roped bucket into the slicks. These slicks were as much as several centimeters thick. At each slick, up to a few hundred grams of emulsion and seawater were placed in precleaned brown glass containers that were immediately placed in a cooler for long-term transport and eventual chemical analysis. Additional samples of the emulsions and seawater were collected in clear plastic containers and also placed in a cooler. A portable Analytical Spectral Devices (ASD) Inc. FieldPro ${ }^{\circledR}$ spectrometer was used to collect in-situ reflectance spectra $(0.35$ to $2.5 \mu \mathrm{m})$ of these slicks off the side of the boat, being careful to keep the side of the boat in shadow to minimize adjacency reflectance effects. Locations for each collection site were measured with a hand-held GPS unit (DWH10-2 was collected at N $28^{\circ}$ 54' 41.5" W 89²0' 39.8"; DWH10-3 was collected at N $28^{\circ} 53^{\prime}$ 57.0" W 89 05' 50.7"; and DWH10-4 was collected at N 28 45' 05.7" W 88 26' 59.7", WGS84).

\section{Spectral Properties of Oil}

Spectral features of oil from the Deepwater Horizon 2010 oil spill in the Gulf of Mexico, vary with the oil:water ratio (called an emulsion) and the emulsion thickness floating on the water surface. The spectral reflectance signature also varies with the areal fractional coverage of oil and water. The features also change due to scattering at the index of refraction boundaries (including oil/air, oil/water, water/air interfaces) and oil and water absorption. Scattering, 
absorption, and transmission compete for limiting the path length of light into and out of the surface where the light can be measured by instruments above the surface.

Reflectance and transmission spectra of natural and prepared oil-water emulsions were measured with an ASD Inc. FS ${ }^{\circledR}$ Hires spectrometer $(0.35$ to $2.5 \mu \mathrm{m})$ in a laboratory by using an incandescent quartz halogen lamp for illumination relative to a spectralon ${ }^{\circledR}$ plate. Reflectance spectra were corrected to absolute reflectance using a National Institute of Standards and Technology (NIST) traceable correction. A portion of a natural sample of the Deepwater Horizon oil emulsion (sample DWH10-3) was heated under a quartz halogen lamp to separate oil from water to determine its oil-to-water ratio (60:40) and provide an oil sample. Then the separated oil was mixed ultrasonically with a quantity of the Gulf of Mexico seawater to produce an emulsion with a 75:25 oil-to-water ratio. A transmission measurement of the separated oil was made using standard spectroscopic transmission cells of various thicknesses and the results, compared to that of pure water, indicated that lamp heating was insufficient to separate enough water to produce water-free oil. To overcome this limitation, another portion of the natural emulsion was heated in 20 minute steps up to $110^{\circ} \mathrm{C}$ to separate the oil and water. This procedure ultimately did provide a sample with a 92:8 oil-to-water ratio. Organic absorptions in this higher temperature oil did not change shape or shift position compared to the lamp-heated sample that was only warm to the touch; thus, the volatilization losses from oil heating did not cause apparent spectral shifts in the infrared.

Other portions of the natural emulsion were rehydrated by hand stirring a measured weight of oil with a measured weight of Gulf of Mexico seawater to create emulsions with 40:60 and 23:77 oil-to-water volume ratios. In this way, natural emulsion DWH10-3 provided a series of prepared emulsions spanning a wide range of oil-to-water ratios for spectral measurement. Spectra from the field-collected samples and laboratory-constructed emulsion mixtures then were used in the volume mapping. Reflectance measurements of various emulsion thicknesses were made at $0.025,0.05,0.1,1.85$, and 4 millimeters, and if we had enough prepared emulsion, at thicknesses of 8, 12, and 16 millimeters. Samples of emulsion were placed between quartz plates with Spectrotech Teflon ${ }^{\circledR}$ spacers of known thickness that allowed reflectance measurements of emulsion thicknesses of $0.025,0.05$, and 0.1 millimeters. A plastic ring gasket and metal washers of known thickness were used to measure reflectance spectra of emulsions in the thicker range listed above. Thicker samples were leveled to the top of the gasket by evenly scraping off excess emulsion with the straight edge of a stainless steel sampler. The optic fiber of the spectrometer was carefully placed to avoid reflections from spacers, the plastic gasket, and metal washers. Reflectance measurements were made by placing the emulsion samples over a hole drilled into a lid screwed onto an empty glass jar painted flat black. This "black hole" device served to capture photons that penetrated the emulsions by not letting them scatter back up through the emulsion sample-similar to what would happen to NIR photons in clear seawater. A few reflectance measurements were made using this same container filled with Gulf of Mexico seawater. No differences in reflectance levels or spectral shapes were observed between the use of seawater or air in the jar.

Several attempts were made to rehydrate portions of natural emulsion DWH10-3 to an oil-to-water ratio of 10:90. None of these attempts were successful. As an alternative, oil separated by heating was hand mixed with Gulf of Mexico seawater and a few drops of dish soap to simulate the effects of oil dispersants. Foamy oil mixtures with oil-to-water ratios of 1:99 and 6:94 were created and their reflectance spectra measured. The 1:99 samples used two drops of 
dish soap in $50 \mathrm{~mL}$ of sample, for a soap abundance of 0.2 percent. This low soap concentration did not add any noticeable spectral features.

The absorption coefficients of three compounds that are representative of the spectral components of oil on water are shown in figure $3 \mathrm{a}$ for pure liquids and for Deepwater Horizon crude oil in figure $3 \mathrm{~b}$. Although the spectra of lighter hydrocarbons vary with molecular size, spectra of decane $(\mathrm{C} 10)$ and higher n-alkanes are similar, while ring compounds like benzene exhibit very different absorptions (Clark and others, 2009). The absorption data shown in figures $3 \mathrm{a}$ and $3 \mathrm{~b}$ and presented by Clark and others (2009) indicate that over the AVIRIS spectral range from 0.35 to $2.5 \mu \mathrm{m}$, absorptions due to the various components vary by several orders of magnitude.

In reflectance, light at different wavelengths penetrates to different depths due to the varying absorption and scattering (Clark and Roush, 1984; Clark and Lucey, 1984; Clark, 1999). This enables different wavelengths to be used to probe to different depths in an oil layer or oil emulsion (fig. 4). In the NIR, clear water is extremely absorbing. Waves which create white foam (for example, white caps on a windy day) create scattering by the water-air interfaces in bubbles limiting the light penetration. Similar effects occur when light encounters oil and oil emulsions. Oil also contains asphaltine compounds that strongly absorb in the blue and UV, and small particles in the oil scatter light and limit penetration, creating the dark reddish color (figs. 1, 2).

Natural marine processes generally cause mixing of oil and seawater, forming emulsions (Thingstad and Pengerud, 1983). This condition creates a nonlinear interaction with light known as an intimate mixture (Hapke, 1981, 1993). Variations in the oil-to-water ratio affect the degree of scattering within the emulsions, creating a wide range of spectral shapes (figs. 5a. 5b). For thin oil layers, the reflected light in the NIR includes a wavelength-dependent loss of light. This loss is illustrated by the spectra in figure 6 that show reflectance spectra for different thicknesses of four emulsions with different oil-to-water ratios. In each of the spectra in figures $5 \mathrm{a}, 5 \mathrm{~b}, 6 \mathrm{a}$, $6 \mathrm{~b}, 6 \mathrm{c}$ and $6 \mathrm{~d}$, the depth and shape of the spectral features varies with oil-to-water ratio and thickness. Examples of the changing characteristics of two spectral features are shown in figures $7 \mathrm{a}$ and $7 \mathrm{~b}$.

If the oil contains aromatic hydrocarbons, additional absorptions might be detected. Figure 6e shows spectra of an oil emulsion with benzene added in the laboratory. Aromatic hydrocarbon absorptions in the near infrared are shifted to shorter wavelengths than those in alkanes (Clark and others, 2009). Benzene, for example, shows aromatic hydrocarbon absorptions near $1.67 \mu \mathrm{m}$ compared to the alkane absorptions near $1.73 \mu \mathrm{m}$. Benzene also shows significant absorption near $2.15 \mu \mathrm{m}$ compared to the $2.3-\mu \mathrm{m}$ alkane absorptions. We searched for these additional spectral features in the AVIRIS data but did not find any patches of aromatic-bearing oil above the noise level.

The spectra in figures 5 and 6 illustrate what visible light (about 0.4 to $0.7 \mu \mathrm{m}$ ) images show for a range of oil emulsion thicknesses and oil-to-water ratios. The spectra of constant oilto-water ratio and varying thickness are very similar at visible wavelengths (fig. 6) for oil:water ratios lower than about 90 percent, while varying the oil-to-water ratio shows significant sensitivity in the spectra at visible wavelengths (fig. 5). This implies that variation in "color" seen in visible light images (for example, fig. 1) of thick oil largely is due to variations in the oilto-water ratio and not to oil thickness. A key exception is very thin sheens with thicknesses comparable to multiples of the wavelength of visible light (a few tens of micrometers thick). 
These colors correspond to the rainbow sheen appearance (Taft and others, 1995) but may represent only a small fraction of the oil in a slick that includes thick emulsions.

The spectra shown in the previous figures are from laboratory studies where oil thickness is uniform. In the ocean spectral measurements of real oil slicks, there can be significant spatial variation in oil-slick thickness on scales from millimeters to kilometers, with clear water exiting beyond the slick's upcurrent delineation of the slick. Note for example, the extreme, fine spatialscale heterogeneity in the photograph of the oil slick emulsion in figure 1, which is part of a larger decameter-scale heterogeneity. As a result, sub-pixel spectral mixing of different surface cover types becomes a significant concern for airborne or satellite remote-sensing analyses.

Field surface observations (fig. 1) show significant heterogeneity on scales from centimeter to tens of meters. Thus, a property observed in AVIRIS data of the oil spill, that was collected at aircraft altitudes of $8.5 \mathrm{~km}$ and higher with pixel sizes of 8.5 meters and larger, includes sub-pixel mixing of oil patches and bluer ocean. The blue ocean increased apparent signal at blue and UV wavelengths. This results from blue light scattering from the ocean. An increase in the short wavelength reflectance also arises from reflection of blue-sky light off of the oil and reflectance of aerosol scattering towards blue and UV wavelengths (fig. 9). To avoid complications from these scattering effects, called path radiance sources, our analysis focuses on NIR wavelengths of 0.8 to $2.4 \mu \mathrm{m}$ where seawater is very dark (that is mostly absorbing) in the absence of sun glint.

\section{Method}

We used the spectral feature identification software Tetracorder (Clark and others, 2003), which has been shown to allow robust identification of different materials by analysis of spectral shapes. Additional oil-specific constraints were defined during the course of this study and incorporated into the spectral analyses. Thick oil (for example, crude oil and water in oil emulsions) is characterized in the NIR by multiple peaks in reflectance from 1 to $1.5 \mu \mathrm{m}$ and diagnostic organic $\mathrm{C}-\mathrm{H}$ absorptions at $1.2,1.7$, and $2.3 \mu \mathrm{m}$, which can be used to determine oilto-water ratio and minimum oil and oil emulsion thicknesses. The continuum-removed absorption shape and the continuum shape were constrained by a parameter called "shoulderness" (fig. 10). Ratios of the reflectance of the continua were also used constrain the spectral characteristics of thick oil patches using absorption features at $0.93 \mu \mathrm{m}$ due to liquid water, at 1.2 and $1.7 \mu \mathrm{m}$ due to organics, for low oil-to-water mixtures with less than 2 percent oil. For thicker path lengths of oil, the features at $1.2,1.7$, and $2.3 \mu \mathrm{m}$ were used along with peak reflectances near $1.3 \mu \mathrm{m}$ and the observed downward trend in the spectra from about 1.3 to $2.2 \mu \mathrm{m}$. For the highest abundance oil (thick oil with low water content, less than a few percent water), the $2.3-\mu \mathrm{m} \mathrm{C}-\mathrm{H}$ absorption becomes too saturated and the 1.2- and 1.7- $\mu \mathrm{m}$ feature shape and shoulderness are used to distinguish those spectra from oil with higher water content. As the correlation coefficient, called the fit, to the least-squares solution decreases, at programmed thresholds, the fit is further decreased by using a simple form of "fuzzy logic" to represent the lower confidence in the identification.

Fuzzy logic thresholding mimics the spectroscopic analyst's idea that, as the correlation between imaging spectrometer data and reference spectra decreases, the confidence in the identification decreases. Rather than a hard threshold used in Clark and others (2003), where the fit was set to zero below the threshold, the fuzzy logic modifies the fit linearly between two thresholds. The fuzzy logic 2-point thresholding modifies the fit according to the equations: 
Fuzz $=1.0$ when parameter $>$ upper threshold $t_{2}$,

Fuzz $=0.0$ when parameter $<$ lower threshold $t_{1}$,

Fuzz $=\left(\mathrm{p}-\mathrm{t}_{1}\right) /\left(\mathrm{t}_{2}-\mathrm{t}_{1}\right)$, where $\mathrm{p}$ is the parameter under test and $\mathrm{t}_{1}<\mathrm{p}<\mathrm{t}_{2}$,

Fit $=$ Fit $\times$ Fuzz.

The various features found in spectra of the oil spill have a range of characteristic values (for example, band depths, shoulderness, or continuum slopes, and so forth), which can drop below thresholds set at different levels. The fuzzy logic thresholding described above gives identification a better chance when interfering mixtures occur. This allows an identification to occur under a broader range of mixture conditions.

NIR spectroscopy probes variable depths into oil: different depths at different wavelengths and different depths depending on the oil-to-water ratio. As the oil-to-water ratio increases, the oil absorbs more light in a shorter path length. Thus, for oil-to-water ratios greater than about 0.5 , the organic absorption bands in the oil spectra become similar at a thickness that decreases as the oil content increases. It becomes more difficult to spectrally determine the thickness of the oil in such high oil-to-water ratios, but it still is possible if the spectral calibration and signal-to-noise ratio are sufficient. Thus, we derive three estimates for the amount of oil detected by the AVIRIS instrument.

Conservative: Oil thickness is assumed limited to a low level where there are greater differences in the spectral discrimination. The thickness limits are dependent on the oil-to-water ratio and are given in table 1 . For example, the spectra in figure $6 \mathrm{~b}$ appear very similar for thicknesses above 1.85 millimeters, so the thickness is limited to 2 millimeters.

Aggressive: Oil thickness is limited to the penetration depth of NIR light that still shows spectral shape differences in laboratory spectra of oil collected from the Deepwater Horizon spill. This assumes that the AVIRIS data have sufficient signal-to-noise ratio needed to distinguish the thicker oil. For example, the spectra in figure $6 \mathrm{~b}$ appear very similar for thicknesses above 1.85 millimeters, but continuum-removed spectral features show small differences between the spectra for 1.85 and 4 millimeters so the thickness is limited to 4 millimeters. Resulting AVIRIS maps show expected zonation of thick oil consistent with anticipated sea surface spatial distributions, implying consistency with the laboratory data and merit in the "aggressive" category.

Possible: Field observations made when oil was collected for this study showed oil thicknesses of 20 millimeters and more in some cases. NIR spectroscopy of high oil:water ratio oil cannot probe this deep, but if field observations are consistent with other areas of high oil-to-water ratio ( $>50$ percent oil), pixels that were determined to be greater than 2 millimeters thick with spectroscopy could in fact be 20 millimeters thick, or more. When the oil-to-water ratio is greater than 90 percent oil, the oil is optically thick at 0.5 millimeters thickness, and that oil could also be much thicker. The "possible" category assumes 20-millimeters thickness for pixels with high oil content and that are NIR optically thick. While this assumption is based on field observations, the field observations are limited, covering only a small portion of the huge area of the spill. Therefore, it is not known how representative this assumption may be. This "possible" category might indicate how much oil might be in the pixels determined to be thick, but it is not known if this is an upper or lower limit due to limited field observations. 
Furthermore, it is unclear if the 2-cm-thick limit is actually an upper limit. Observations in the Coal Oil Point seep field have shown that where spreading is opposed by other forces, such as current sheers, on small scales (submeter), oil thicknesses greater than $2 \mathrm{~cm}$ occur (Ira Leifer, oral communication, 2010). In this much larger Deepwater Horizon spill, greater thicknesses may be feasible on much larger spatial scales.

\section{AVIRIS Data}

The three oil volume estimates (conservative, aggressive, and possible) were calculated from the AVIRIS (Green and others, 1998) data, which were collected from a mission flown over the 2010 Deepwater Horizon oil spill in the Gulf of Mexico. AVIRIS data from May 17 are shown for a region that includes the well head source of the spill (fig. 11, 12). The method used to map oil is as follows.

AVIRIS was flown 1 to 3 hours after local solar noon to allow cloud cover to burn off and solar elevation to decrease sufficiently to avoid reflecting sun glint into the near nadirlooking spectrometer (Field Of View, FOV=34 degrees). Flight lines were oriented in the direction of the sun, or opposite it, to further minimize sun glint because the sun was at a relatively high elevation at that time of year. Wave heights were less than one-half meter, which, in combination with flight lines oriented perpendicular $\left( \pm 30^{\circ}\right)$ to the wave crest direction also minimized wave-induced sun glint. Wave heights over this threshold caused significant sun glint on other flight days (for example, on May 10). Glint produces a positive offset in AVIRIS spectra that can interfere with spectral determination of oil volume. Five AVIRIS flight lines that formed a non-overlapping grid over the core of the oil spill were chosen for analysis. Because the spill covered a large area on May 17, AVIRIS overflights on the ER-2 aircraft at an altitude of 8,500 $\mathrm{m}$ were unable to cover the whole spill in one day. One disadvantage of collecting spectral data at lower sun elevations is enhanced absorption by atmospheric gases, which slightly reduces the width of usable atmospheric windows bordering the $0.9,1.2,1.5,1.9$, and $3 \mu \mathrm{m}$ water vapor absorptions. This was a necessary tradeoff for virtually cloud- and sunglint-free data over the oil spill.

(1) AVIRIS radiance data were converted to surface reflectance using a two-step process described by Clark and others (2002). Step 1 used a radiative transfer model to correct absorption by atmospheric gases, scattering by atmospheric aerosols, and to remove the solar spectrum to derive apparent surface reflectance. Because existing radiative transfer models are imperfect, vegetation-free areas on beaches were measured spectrally with an ASD portable field spectrometer, and the residuals from the radiative transfer model were corrected using the field-developed standards. Each AVIRIS flight included an overflight of one or more field standard calibration sites.

The three AVIRIS calibration sites were selected based on reconnaissance using Google Earth $^{\mathrm{TM}}$. The calibration sites were selected because of their high reflectance and close proximity to the ocean where atmospheric aerosol conditions would be closest to those experienced near the offshore incident site. Beaches near Pensacola, Florida, and Gulfport, Mississippi, covered an area large enough to accommodate a minimum of sixteen 20-meter pixels that would be scanned by AVIRIS flying on the ER-2 at 19,800 m (65,000 feet) altitude. Although a beach calibration site at Dauphin Island, Alabama was only wide enough to accommodate two rows of 8.5-meter pixels scanned by AVIRIS flying on the ER-2 at 8,500-meter (28,000 feet) altitude, it was 
located just north of the incident site so it could be easily flown by extending a flight line north from the grid of low-altitude flight lines being flown over the incident site. The three calibration sites are geographically separated to maximize the possibility of having at least one cloud-free site during each day of AVIRIS flights. Each rectangular calibration site was spectrally measured on foot using a portable ASD spectrometer. Spectra of the ground surface were measured continually while systematically walking across each calibration site under clear sky conditions. Ground spectra were measured relative to Spectralon ${ }^{\circledR}$, with reference measurements repeated often to avoid introducing noise from variable atmospheric water into the ground spectra. A minimum of 200 ground spectra were measured at each calibration site. A Mylar ${ }^{\circledR}$ standard was measured at each site to check the accuracy of the portable field spectrometer's wavelength calibration. Hand samples of representative surface materials were collected at each site for future reference. Corners of the calibration sites were georeferenced using a GPS unit, and photographs documenting each site were collected. The Dauphin Island calibration site was used to correct May 17, 2010, AVIRIS data because this site was relatively dry after torrential rains soaked the Gulfport calibration site. Because AVIRIS was flown over the spill in the late afternoon (for example, several hours after local solar noon), sunlight reflecting off the ocean surface traversed a relatively longer path through the atmosphere, resulting in stronger atmospheric residuals in the AVIRIS radiance data.

(2) Tetracorder (Clark and others, 2003) was used to identify the spectral signatures of oil of different thicknesses and oil-to-water ratios. Twenty-nine oil and emulsion reference spectra were used to make this identification (table 1). In addition, reference spectra for oil+benzene were used to search for aromatic hydrocarbons (table 1) but were not used in the volume estimate. Reference spectra for seawater, plants, clouds, paint/plastics, and other materials were also used to distinguish oil from oil-free ocean, ships, and vegetated coastlines. No aromatic hydrocarbon containing oil was detected beyond a few random pixels attributed to noise.

Determination of the dominant spectral signature in each AVIRIS pixel was based on the highest correlation coefficient for a least-squares linear regression analysis, as described in Clark and others (2003), with constraints due to shoulderness, continuum levels, continuum slopes, and fuzzy logic thresholding.

(3) Each of the 29 reference spectra resulted in the creation of 29 sets of output images from Tetracorder, each showing the pixel locations where that compound/mixture was found. The thicknesses were then computed for each image pixel based on conservative, aggressive, and "possible" estimates (table 1), producing three thickness images. Because NIR light only probes to a finite depth (a few millimeters depending on the oil-to-water ratio), the thick oil derived in this study for the conservative and aggressive estimates are only LOWER LIMITS for the abundances of oil at the ocean surface. The thicknesses and oil-to-water ratio are dependent on the detection of spectral features and spectral shape and not on reflectance level (albedo). Albedo is used in step 4 to derive fractional area.

(4) By comparing the albedo of the best-fit reference spectrum found in step 3 to that of each AVIRIS pixel, the fractional area is determined, assuming the near-IR reflectance of ocean water in the pixel is zero. If the ocean reflectance is above zero, the resulting 
oil volume is a lower limit; that is, it is conservative. Ocean reflectance can rise in the infrared, for example, due to sun glint. Significant sun glint in a pixel can cause a slight overestimation of oil fractional area and, thus, oil volume within that pixel. We designed the AVIRIS data collection to minimize sun glint.

(5) The fractional area from step 4 multiplied by the oil volume from table 1 gives the volume per pixel. A summation of all image pixels containing oil gives the total oil volume detected on the surface in areas covered by the sensor.

\section{Volume/pixel $=$ area of pixel $\mathbf{x}$ thickness $\mathrm{x}$ oil fraction $\mathrm{x}$ areal fraction of oil}

Table 2 shows the results for each AVIRIS flight line (runs \# 08, 09, 10, 11, and 14). Runs 12 and 13 are not included due to clouds and because those lines did not cover areas with thick oil. Further, run 08 contained some sun glint, and those areas were masked and not included in the analysis.

\section{Results and Discussion}

Spectra from AVIRIS show a wide range of spectral signatures (figs. 12, 13a, 13b). The color composite image in figure 12 shows many areas with faint red colors, but those areas have only trace oil, as indicated by extracted AVIRIS spectra and the example spectra in figure 12. Only the pixels that are more intense red or orange contain significant amounts of surface oil. The Tetracorder strategy separated oil, ocean, clouds, boats, and platforms well; example spectra are shown in figures $13 \mathrm{a}$ and $13 \mathrm{~b}$.

Example Tetracorder results are shown in figures $14 \mathrm{a}, 14 \mathrm{~b}, 15 \mathrm{a}$, and $15 \mathrm{~b}$. The analysis shows that thick oil occurs in fewer areas than is apparent by visible color. This follows from the spectral properties of oil discussed previously where we showed that visible color is largely controlled by oil-to-water ratio and not oil emulsion thickness for thick oil. The results also show zones of oil-to-water ratio within the ribbons of thick oil as might be expected (figs. 14a, and 14b). Note that in the region of the incident site (fig. 14a) the oil-to-water ratio was low, likely due at least in part to the use of dispersants. In contrast, analysis of AVIRIS imagery to the west-southwest of the incident site (fig. 14b) showed oil slicks with regions of substantially higher oil-to-water ratios.

Example images of oil sub-pixel areal fraction, thickness, and volume per pixel are shown in figures $15 \mathrm{a}$ and $15 \mathrm{~b}$. At first glance, oil thickness images can be a bit deceptive because NIR spectroscopy probes deeper as the oil content of emulsions decreases. Thicker water-rich emulsions can result in a small total volume compared to thin oil-rich emulsions. The volume images emphasize areas with the most oil. These areas should be targeted for cleanup because they could have the greatest impact on coastal ecosystems as they approach shore.

The results shown here highlight the utility of imaging spectrometer measurements across the visible to NIR wavelengths for quantifying oil spills in the ocean. The method presented here provides a fundamental image analysis method, using oil-related absorption features, as a means for detecting thick oil and quantifying their oil volume.

Using the spectral method for mapping thick oil established by this study, data from future imaging spectrometer flights can be analyzed faster to provide guidance for cleanup. Imaging spectroscopy data require a significant amount of disk space. This poses challenges for moving the spectral data from aircraft recording systems over to computers for analysis. 
Calibration to apparent reflectance requires several hours of work by two to three people after the ground calibration site has been established. Flying the AVIRIS instrument required a team of pilots and support personnel as well as people planning each day's data acquisition. After the plane landed, one person calibrated the data to radiance. The radiance data then required two people to do the atmospheric absorption and scattering removal to derive surface reflectance. Once calibrated, Tetracorder analysis and volume estimates of each line required about 0.5 to 1 hour per line on a modern PC running Linux (time depends on line length and disk speed). Evaluating the results, geo-rectifying the lines and making the map products can take several hours per line. Together it can take 24 to 48 hours to analyze data by the experienced team represented in the author list.

Different oil spills will likely have different oil chemical compositions; thus, the reference spectra used in this study may not be applicable to abundance derivation in other spills. If that is the case, each spill would need to have samples of the spill collected and analyzed for entry into the Tetracorder expert system. The effort for the current spill required about 1,500 person hours of work by a team of six, including measurement of field samples, preparation of additional laboratory samples, and development of the mapping method.

Results from this study were limited by available samples from the spill. The fieldcollected oil emulsions and the laboratory constructed oil and oil emulsions have some gaps in the observed spectral trends, notably the range of 60 to 90 percent oil where we needed better coverage and we had no samples that covered 6 to 23 percent oil-to-water ratio. Some of the spectra extracted from the AVIRIS data showed spectral properties that appeared to fall in these gaps. Some AVIRIS spectra were binned into the nearest oil fraction and thickness, but a limited number of others may not have been identified at all. This is another reason why the derived volumes are lower limits. BP was to provide crude oil samples but they were not supplied during the analytical phase of this study, and our attempts to obtain dispersant were also unsuccessful. While this study was in review, BP provided samples of crude oil from the leaking well, but attempts to obtain dispersant (for example, Corexit ${ }^{\circledR}$ ) from Nalco, free of analytical constraints, were unsuccessful.

Samples of crude oil and oil mixed with dispersant need to be analyzed in order to properly map them with imaging spectroscopy. Thus, additional oil might be found as the remaining compositional gaps are filled and representative emulsion and dispersant samples are measured and incorporated into the Tetracorder command file. Again, it is emphasized that the volumes derived in this paper are lower limits.

\section{Extrapolating to the Entire Spill}

The Deepwater Horizon spill in May 2010 was too large to cover with AVIRIS in a single day. As a result, the AVIRIS system subsampled the spill. To extrapolate to the entire spill, we used MODIS imagery to estimate the total spill area. Figure 16a shows the MODIS data for May 17, 2010, and figure 16b shows the classification of the image into potentially thicker areas (shown as orange + green) and lower level oil and oil sheen (gray). The AVIRIS lines that overlap the orange region are green. The MODIS thick region (orange) covers 3,363 $\mathrm{km}^{2}$ (table 2), and the lower level oil and sheen cover an additional 14,400 $\mathrm{km}^{2}$ on May 17. Note, however, that MODIS imagery, at $250 \mathrm{~m} / \mathrm{pixel}$, is rather low resolution, and some smaller areas of thick oil may not have been detected. This too makes the estimate from AVIRIS data a lower limit. The AVIRIS data cover $966.6 \mathrm{~km}^{2}$ in the "orange" region, for a coverage ratio of 0.287. We assumed that the areas not covered by AVIRIS have similar amounts of oil, and we 
extrapolate the AVIRIS oil detected by dividing by 0.287 then rounding the numbers to two significant digits.

The extrapolation of the AVIRIS results to the total spill gives 66,000 barrels (conservative) and 120,000 barrels (aggressive) and are lower limits for the amount of thick oil at the sea surface, and 500,000 possible barrels. These values do not include oil sheen, oil not detected by this analysis, burned or evaporated oil components, oil dispersed by natural or anthropogenic mechanisms, nor underwater oil. Labson and others (2010) estimated these other values to get a leak rate from the source region.

\section{Conclusions}

We have demonstrated that NIR spectroscopy can probe several millimeters into oil and that the spectral properties can be used to simultaneously solve for oil-to-water ratio, oil thickness up to the optically thick limit, which varies with the oil:water ratio, and the sub-pixel areal fraction of oil, enabling the total volume of oil to be derived for a given area. Mapping of an oil spill can be done by aircraft imaging spectrometers, but for a large spill like that from the Deepwater Horizon, complete coverage in a single day is not possible with existing technology. Wider swath instruments are needed for better coverage in such situations, from aircraft or satellite. The sensors, whether aircraft or satellite based, must obtain data with minimum sun glint. MODIS and Landsat data over the Deepwater Horizon oil spill often included sun glint.

The results from table 2 show that this analysis approach on AVIRIS data detected about 19,000 (conservative) to 34,000 (aggressive) barrels of oil (lower limits) on May 17, 2010. AVIRIS covered only about 30 percent of the area of the thickest parts of the spill based on projections from the AVIRIS covered area to the apparent spill area based on MODIS imagery for May 17 (figs. 16a, 16b). If the AVIRIS results are representative of the areas not covered, this implies that the ocean surface was covered with lower limits of about 66,000 to 120,000 barrels of oil. Because near-infrared spectroscopy only penetrates into the upper few millimeters of oil, and oil was observed in patches a couple of centimeters thick during collection of the samples, both the conservative and aggressive values represent lower limits. That leads to a projection of a possible 500,000 barrels of thick oil on the surface. Considering the evaporation loss of volatile organics, spreading of the oil into a thin sheen not detected by this study, and reports of subsurface oil, the oil detected by AVIRIS in this study is significant. The total volume of oil in the Gulf of Mexico on May 17, is likely to be even greater.

\section{Acknowledgments}

Special thanks go to Sonia Gallegos, Naval Research Labs, for helping to arrange and participating in a sampling trip out to the oil spill, to BP for providing the boat, and to Entrix for help in collecting emulsion samples. Thanks also go to William Benzel (USGS) for his ideas and help with the preparation of oil-water emulsions. We also thank the ER-2 pilots and aircraft team who collected superb data for this study. A portion of the research described was carried out at the Jet Propulsion Laboratory, California Institute of Technology, under a contract with the National Aeronautics and Space Administration. 


\section{References}

ASCE, 1996, State of the art review of modeling transport and fate of oil spill (task committee on modeling oil spills of the water resources engineering division): Journal of Hydraulic Engineering., v. 122, no. 11, p. 594-609.

Brown, R.H., Soderblom, L.A., Stoderblom, J.M., Clark, R.N., Jaumann, R., Barnes, J.W., Sotin, C., Buratti, B., Baines, K.H., and Nicholson, P.D., 2008, The identification of liquid ethane in Titan's Ontario Lacus: Nature, v. 454, no. 7204, p. 607-610, doi:10.1038/nature07100.

Clark, R.N., Curchin, J.M., Barnes, J.W., Jaumann, R., Soderblom, Larry, Cruikshank, D.P., Brown, R.H., Rodriguez, S., Lunine, J., Stephan, K., Hoefen, T.M., Le Mouelic, S., Sotin, C., Baines, K.H., Buratti, B., and Nicholson, P., in press, Detection and mapping of hydrocarbon deposits on Titan: Journal of Geophysical Research.

Clark, R.N., Curchin, J.M., Hoefen, T.M., and Swayze, G.A., 2009, Reflectance spectroscopy of organic compounds I-Alkanes: Journal of Geophysical Research, v. 114, p. E03001, doi:10.1029/2008JE003150. http://www.agu.org/pubs/crossref/2009/2008JE003150.shtml.

Clark, R.N., and Lucey, P.G., 1984, Spectral properties of ice-particulate mixtures and implications for remote sensing I-Intimate mixtures: Journal of Geophysical Research, V. 89, p. 6341-6348.

Clark, R.N., and Roush, T.L., 1984, Reflectance spectroscopy-Quantitative analysis techniques for remote sensing applications: Journal of Geophysical Research, v. 89, no. B7, p. 63296340.

Clark, R.N., Swayze, G.A., Livo, K.E., Kokaly, R.F., Sutley, S.J., Dalton, J.B., McDougal, R.R., and Gent, C.A., 2003, Imaging spectroscopy_Earth and planetary remote sensing with the USGS Tetracorder and expert systems: Journal of Geophysical Research, v. 108, no. E12, 5131, doi:10.1029/2002JE001847, p. 5-1 to 5-44. (Also available at http://speclab.cr.usgs.gov/PAPERS/tetracorder.)

Clark, R.N., 1999, Chapter 1-Spectroscopy of rocks and minerals, and principles of spectroscopy, in Manual of remote sensing, volume 3: Remote Sensing for the Earth Sciences, Rencz, A.N., ed.: John Wiley and Sons, New York, p 3-58.

Clark, R.N., Swayze, G., Livo, E., Kokaly, R., King, T.V.V., Dalton, B., Vance, S., Rockwell, B., Hoefen, T., and McDougal, R., 2002, Surface reflectance calibration of terrestrial imaging spectroscopy data-A tutorial using AVIRIS, in Green, R.O., ed., JPL Airborne Earth Science Workshop, 11th, Pasadena, Calif., 2002, Proceedings: JPL Publication 03-4, p. 43-63. (Also available at http://speclab.cr.usgs.gov/PAPERS.calibration.tutorial.)

Clark, R.N., Swayze, G.A., Leifer, I., Livo, K.E., Lundeen, S., Eastwood, M., Green, R.O., Kokaly, R., Hoefen, T., Sarture, C., McCubbin, I., Roberts, D., Steele, D., Ryan, T., Dominguez, R., Pearson, N., and the Airborne Visible/Infrared Imaging Spectrometer (AVIRIS) Team, 2010, A method for qualitative mapping of thick oil spills using imaging spectroscopy: U.S. Geological Survey Open-File Report 2010-1101, http://pubs.usgs.gov/of/2010/1101/. 
Delvigne, G.A.L., 1987, Droplet size distribution of naturally dispersed oil, in Fate and effects of oil in marine ecosystems, edited by Kuiper, J., and Van den Brink, W.J.: Martinus Nijhoff Publications., Boston, p. 29-40.

Elliot, G., 1999, Shunning the tar baby_California Coast and Ocean: State of California Coastal Conservancy, v. 15 (Autumn).

Engelhardt, F.R., 1987, Assessment of the vulnerability of marine mammals to oil pollution, in Fate and effects of oil in marine ecosystems, edited by Kuiper, J., and Van den Brink, W.J.: Martin Nijhoff Publishers, Dordrecht, Lancaster, Boston, p. 101-115.

Green, R.O., Eastwood, M.L., Sarture, C.M., Chrien, T.G., Aronsson, M., Chippendale, B.J., Faust, J.A., Pavri, B.E., Chovit, C.J., Solis, M., Olah, M.R., and Williams, O., 1998, Imaging spectroscopy and the airborne visible/infrared imaging spectrometer (AVIRIS): Remote Sensing of Environment, v. 65, p. 227-248.

Hapke, B., 1981, Bidirectional reflectance spectroscopy 1. Theory: Journal of Geophysical Research, v. 86, p. 3039-3054.

Hapke, B., 1993, Introduction to the theory of reflectance and emittance spectroscopy: New York, Cambridge University Press, 455 p.

Hornafius, J.S., Quigley, D.C., and Luyendyk, B.P., 1999, The world's most spectacular marine hydrocarbons seeps (Coal Oil Point, Santa Barbara Channel, California)—Quantification of emissions: Journal Geophysical Research-Oceans, v. 104, p. 20703-20711.

Labelle, R.P., and Danenberger, E.P., 1997, Oil-spill research program of the US Minerals Management Service: Spill Science and Technology Bulletin, v. 4, no. 2, p. 107-111.

Labson, V.F., Clark, R.N., Swayze, G.A., Hoefen, T.M., Kokaly, R., Livo, K.E., Powers, M.H., Plumlee, G.S., and Meeker, G.P., 2010, Estimated lower bound for leak rates from the Deepwater Horizon spill-Interim report to the Flow Rate Technical Group from the Mass Balance Team: U.S. Geological Survey Open-File Report 2010-1132, 4 p. http://pubs.usgs.gov/of/2010/1132/.

Lehr, J.W., and Simecek-Beatty, D., 2000, The relation of langmuir circulation processes to the standard oil spill spreading, dispersion, and transport algorithms: Spill Science and Technology Bulletin, v. 6, nos. 3-4, p. 247-253.

Leifer, I., Luyendyk, B., and Broderick, K., 2006, Tracking an oil slick from multiple natural sources, coal oil point, California: Marine and Petroleum Geology, v. 23, no. 5, p. 621-630.

NRC, 2003, Oil in the sea III-Inputs, fates, and effects: National Academy of Sciences, Washington, D.C., 265 p.

Reed, M., Aamo, O.M., and Daling, P.S., 1995, Quantitative analysis of alternate oil spill response strategies using oscar: Spill Science and Technology Bulletin, v. 2, no. 1, p. 67-74.

Riazi, M.R., and Al-Enezi, G.A., 1999, Modeling of the rate of oil spill disappearance from seawater for Kuwaiti crude and its products: Chemical Engineering Journal, v. 73, p. 161-172.

Spies, R.B., Stegeman, J.J., Hinton, D.E., Woodin, B., Smolowitz, R., Okihiro, M., and Shea, D., 1996, Biomarkers of hydrocarbon exposure and sublethal efects in embiotocid fishes from 
a natural petroleum seep in the Santa Barbara channel: Aquatic Toxicology, v. 34, no. 3, p. 195-219.

Taft, D.G., Egging, D.E., and Kuhn, H.A., 1995, Sheen surveillance-An environmental monitoring program subsequent to the 1989 Exxon Valdez shoreline cleanup, in Wells, Peter G., Butler, James N., and Hughes, Jane S., eds., Exxon Valdez oil spill—Fate and effects in Alaskan waters: Philadelphia, American Society for Testing and Materials, ASTM STP 1219, $955 \mathrm{p}$.

Thingstad, T., and Pengerud, B., 1983, The formation of "Chocolate Mousse" from Statfjord crude oil and seawater: Marine Pollution Bulletin, v., 14, no. 6, p. 214-216. 
Table 1. Assigned volume values to lab spectra.

\begin{tabular}{|c|c|c|c|c|c|c|c|c|}
\hline $\begin{array}{l}\text { Reference } \\
\text { sp0 } 484 \\
\text { ID\# }\end{array}$ & Oil:Water & $\begin{array}{c}\text { Lab sample } \\
\text { thickness } \\
(\mathrm{mm})\end{array}$ & $\begin{array}{c}\text { Cons. } \\
(\mathrm{mm})\end{array}$ & $\frac{\text { signed }}{\text { Aggr. }}$ & $\begin{array}{l}\text { thickness } \\
\text { Possible } \\
\text { (mm) }\end{array}$ & $\frac{\text { Full }}{\text { Conserv. }}$ & $\frac{\text { pixel volu }}{\text { ers/pixel }}$ & $\frac{\text { dme }}{\text { Possible }}$ \\
\hline 16006 & $92: 8$ & 0.1 & 0.1 & 0.1 & 0.1 & 6.7 & 6.7 & 6.7 \\
\hline 16007 & $92: 8$ & 0.5 & 0.5 & 0.5 & 20 & 33.2 & 33.2 & 1329 \\
\hline 16008 & $92: 8$ & 1.85 & 1.5 & 1.9 & 20 & 99.7 & 126 & 1329 \\
\hline 16009 & $92: 8$ & 4 & 2 & 4 & 20 & 133 & 266 & 1329 \\
\hline 14464 & $80: 20$ & 4 & 1.0 & 1.5 & 20 & 57.8 & 86.7 & 1156 \\
\hline 13832 & $75: 25$ & 8 & 1.5 & 1.5 & 20 & 81.3 & 81.3 & 1084 \\
\hline 9820 & $60: 40$ & 0.025 & 0.0125 & 0.025 & 0.025 & 0.5 & 1.1 & 1.1 \\
\hline 9823 & $60: 40$ & 0.05 & 0.03 & 0.05 & 0.05 & 1.3 & 2.2 & 2.2 \\
\hline 9816 & $60: 40$ & 0.1 & 0.1 & 0.1 & 0.1 & 4.3 & 4.3 & 4.3 \\
\hline 16657 & $60: 40$ & 0.5 & 0.5 & 0.5 & 0.5 & 21.7 & 21.7 & 21.7 \\
\hline 3749 & $60: 40$ & 1.85 & 1.5 & 1.9 & 1.9 & 65.0 & 82.4 & 82.4 \\
\hline 16656 & $60: 40$ & 4.0 & 2 & 4 & 20 & 86.7 & 173 & 867 \\
\hline 13694 & $40: 60$ & 0.05 & 0.03 & 0.05 & 0.05 & 0.9 & 1.4 & 1.4 \\
\hline 11283 & $40: 60$ & 0.1 & 0.1 & 0.1 & 0.1 & 2.9 & 2.9 & 2.9 \\
\hline 11285 & $40: 60$ & 0.5 & 0.5 & 0.5 & 0.5 & 14.5 & 14.5 & 14.5 \\
\hline 11288 & $40: 60$ & 1.85 & 1.5 & 1.9 & 1.9 & 43.3 & 54.9 & 54.9 \\
\hline 11289 & $40: 60$ & 4 & 2 & 4 & 20 & 57.8 & 116 & 578 \\
\hline 13689 & $23: 77$ & 0.025 & 0.0125 & 0.025 & 0.025 & 0.2 & 0.4 & 0.4 \\
\hline 13692 & $23: 77$ & 0.05 & 0.03 & 0.05 & 0.05 & 0.5 & 0.8 & 0.8 \\
\hline 13695 & $23: 77$ & 0.1 & 0.1 & 0.1 & 0.1 & 1.7 & 1.7 & 1.7 \\
\hline 13698 & $23: 77$ & 0.5 & 0.5 & 0.5 & 0.5 & 8.3 & 8.3 & 8.3 \\
\hline 13699 & $23: 77$ & 1.85 & 1.5 & 1.9 & 1.9 & 24.9 & 31.6 & 31.8 \\
\hline 13700 & $23: 77$ & 4 & 2 & 4 & 20 & 33.2 & 66.5 & 332 \\
\hline 16659 & $6: 94$ & 5 & 1 & 3 & 3 & 4.3 & 13 & 13 \\
\hline 13703 foam & n $1.3: 98.7$ & 28 & 0.1 & 1 & 1 & 0.09 & 0.9 & 0.9 \\
\hline $\begin{array}{l}13704 \\
13703 \\
16656 \\
16656\end{array}$ & $\begin{array}{c}1.3: 98.7 \\
1.3: 98.7 * \\
60: 40 \star \star \\
60: 40 * \star\end{array}$ & $\begin{array}{r}28 \\
+28 \\
4 \\
4\end{array}$ & $\begin{array}{l}1 \\
0.1 \\
0.08 \\
0.06\end{array}$ & $\begin{array}{l}20 \\
1 \\
0.16 \\
0.12\end{array}$ & $\begin{array}{l}20 \\
1 \\
0.16 \\
0.12\end{array}$ & $\begin{array}{l}0.9 \\
0.09 \\
3.4 \\
4.3\end{array}$ & $\begin{array}{r}18.8 \\
0.9 \\
6.9 \\
8.7\end{array}$ & $\begin{array}{r}18.8 \\
0.9 \\
6.9 \\
8.7\end{array}$ \\
\hline $\begin{array}{l}14461 \\
14462\end{array}$ & $\begin{array}{l}60: 40+10 \text { Ben } \\
60: 40+18 \text { Ben }\end{array}$ & $\begin{array}{l}6 \\
6\end{array}$ & - & - & $\begin{array}{l}- \\
-\end{array}$ & $\begin{array}{l}- \\
-\end{array}$ & - & - \\
\hline
\end{tabular}

* Same reference spectrum \#13703 but the continuum from 0.67 to 2.4 microns is added for a shape match to find other foamy oil missed by the previous entry for \#13703 which required tighter constraints on $\mathrm{C}-\mathrm{H}$ feature detection.

** These 60:40 entries are areal mixtures computed from the $2 \mathrm{~mm}$ thick spectra with areal fractions of 0.08 and 0.06 , giving an equivalent thicknesses, if spread uniformly over a pixel:

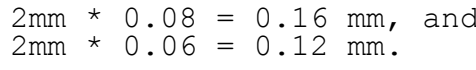


Table 2. Oil volume calculation from May 17 over flight.

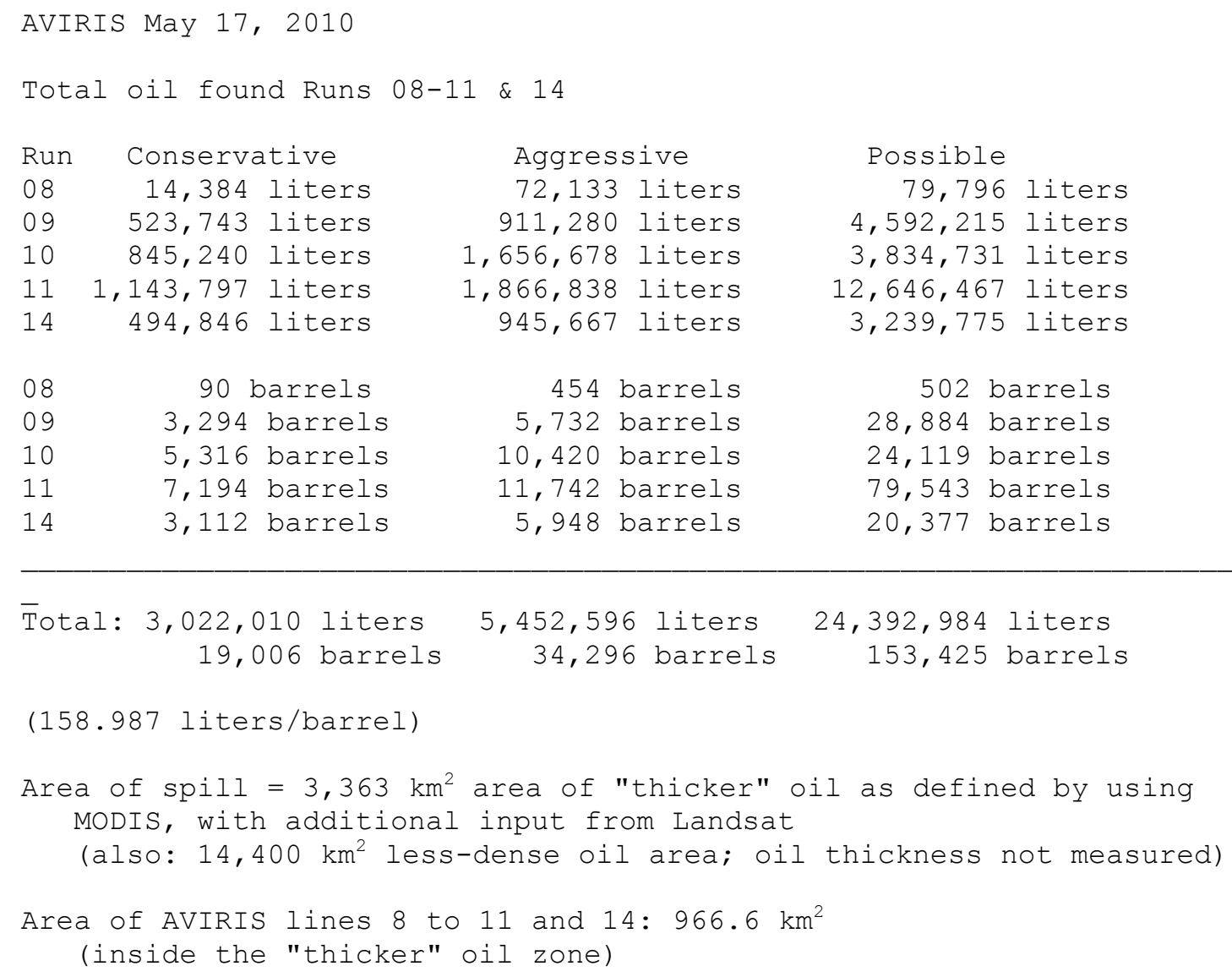

\begin{tabular}{|c|c|c|c|c|c|c|c|}
\hline & \multicolumn{3}{|c|}{ Thickness (mm) } & \multicolumn{3}{|c|}{ Volume (liters/pixel) } & Pixels \\
\hline Oil: H2O & Cons. & Aggr. & POSS. & Conserv. & Aggress. & Possible & mapped \\
\hline $92: 8$ & 0.10 & 0.10 & 0.10 & 13.3 & 13.3 & 13.3 & 2 \\
\hline $92: 8$ & 0.50 & 0.50 & 20.00 & 0.0 & 0.0 & 0.0 & 0 \\
\hline $92: 8$ & 1.50 & 1.90 & 20.00 & 347.5 & 440.1 & $4,633.1$ & 11 \\
\hline $92: 8$ & 2.00 & 4.00 & 20.00 & 0.0 & 0.0 & 0.0 & 0 \\
\hline $80: 20$ & 1.00 & 1.50 & 20.00 & 60.2 & 90.2 & $1,203.0$ & 9 \\
\hline $75: 25$ & 1.50 & 1.50 & 20.00 & 66.3 & 66.3 & 884.5 & 1 \\
\hline $60: 40$ & 0.01 & 0.03 & 0.03 & 0.0 & 0.0 & 0.0 & 0 \\
\hline $60: 40$ & 0.03 & 0.05 & 0.05 & 0.0 & 0.0 & 0.0 & 0 \\
\hline $60: 40$ & 0.10 & 0.10 & 0.10 & 0.0 & 0.0 & 0.0 & 0 \\
\hline $60: 40$ & 0.50 & 0.50 & 0.50 & 0.0 & 0.0 & 0.0 & 0 \\
\hline $60: 40$ & 1.50 & 1.90 & 1.90 & 265.7 & 336.5 & 336.5 & 8 \\
\hline $60: 40$ & 2.00 & 4.00 & 20.00 & 85.9 & 171.8 & 858.9 & \\
\hline $40: 60$ & 0.03 & 0.05 & 0.05 & 0.0 & 0.0 & 0.0 & 0 \\
\hline $40: 60$ & 0.10 & 0.10 & 0.10 & 0.0 & 0.0 & 0.0 & \\
\hline $40: 60$ & 0.50 & 0.50 & 0.50 & 0.0 & 0.0 & 0.0 & 0 \\
\hline $40: 60$ & 1.50 & 1.90 & 1.90 & 0.0 & 0.0 & 0.0 & \\
\hline $40: 60$ & 2.00 & 4.00 & 20.00 & 49.4 & 98.9 & 494.4 & 2 \\
\hline
\end{tabular}




\begin{tabular}{|c|c|c|c|c|c|c|c|c|}
\hline $23: 77$ & 0.01 & 0.03 & 0.03 & 0.0 & 0.0 & 0.0 & 0 & \\
\hline $23: 77$ & 0.03 & 0.05 & 0.05 & 0.0 & 0.0 & 0.0 & 0 & \\
\hline $23: 77$ & 0.10 & 0.10 & 0.10 & 0.0 & 0.0 & 0.0 & 0 & \\
\hline $23: 77$ & 0.50 & 0.50 & 0.50 & 63.0 & 63.0 & 63.0 & 28 & \\
\hline $23: 77$ & 1.50 & 1.90 & 1.90 & $1,346.4$ & $1,705.5$ & $1,705.5$ & 166 & \\
\hline $23: 77$ & 2.00 & 4.00 & 20.00 & 57.0 & 114.0 & 570.0 & 9 & \\
\hline $6: 94$ & 1.00 & 3.00 & 3.00 & $8,154.4$ & $24,463.3$ & $24,463.3$ & 3,613 & \\
\hline $1: 99$ & 0.10 & 1.00 & 1.00 & 16.6 & 166.3 & 166.3 & 754 & \\
\hline $1: 99$ & 1.00 & 20.00 & 20.00 & $1,890.4$ & $37,807.4$ & $37,807.4$ & 3,384 & \\
\hline $1: 99$ & 0.10 & 1.00 & 1.00 & 332.7 & $3,326.6$ & $33,26.6$ & 11,778 & low level \\
\hline $60: 40$ & 0.08 & 0.16 & 0.16 & 74.8 & 149.7 & 149.7 & 73 & low level \\
\hline $60: 40$ & 0.06 & 0.12 & 0.12 & $1,560.1$ & $3,120.2$ & $3,120.2$ & 1,274 & trace \\
\hline
\end{tabular}

Total volume found:

$\begin{array}{llr}14,384 \text { liters }(\text { conservative) } & = & 90 \text { barrels } \\ 72,133 \text { liters (aggressive) } & = & 454 \text { barrels } \\ 79,796 \text { liters (possible) } & = & 502 \text { barrels }\end{array}$

AVIRIS Run 09: 677 samples x 17,893 scanlines

170,216 pixels mapped out of $12,113,561$ total image pixels.

\begin{tabular}{|c|c|c|c|c|c|c|c|c|}
\hline & \multicolumn{3}{|c|}{ Thickness (mm) } & \multicolumn{3}{|c|}{ Volume (liters/pixel) } & Pixels & \\
\hline Oil: H2O & Cons. & - Aggr. & - POSS. & Conserv. & Aggress. & Possible & mapped & \\
\hline $92: 8$ & 0.10 & 0.10 & 0.10 & 598.6 & 598.6 & 598.6 & 93 & \\
\hline $92: 8$ & 0.50 & 0.50 & 20.00 & $2,209.3$ & 2209.3 & $88,371.7$ & 148 & \\
\hline $92: 8$ & 1.50 & 1.90 & 20.00 & $16,648.0$ & $21,087.5$ & $221,973.4$ & 194 & \\
\hline $92: 8$ & 2.00 & 4.00 & 20.00 & 50.0 & 100.0 & 499.8 & 1 & \\
\hline $80: 20$ & 1.00 & 1.50 & 20.00 & $125,471.6$ & $188,207.3$ & $2,509,431.2$ & 3,230 & \\
\hline $75: 25$ & 1.50 & 1.50 & 20.00 & $41,065.9$ & $41,065.9$ & $547,545.4$ & 1,348 & \\
\hline $60: 40$ & 0.01 & 0.03 & 0.03 & 0.3 & 0.6 & 0.6 & 1 & \\
\hline $60: 40$ & 0.03 & 0.05 & 0.05 & 14.7 & 29.5 & 29.5 & 44 & \\
\hline $60: 40$ & 0.10 & 0.10 & 0.10 & 27.7 & 27.7 & 27.7 & 22 & \\
\hline $60: 40$ & 0.50 & 0.50 & 0.50 & $18,687.4$ & $18,687.4$ & $18,687.4$ & 3,099 & \\
\hline $60: 40$ & 1.50 & 1.90 & 1.90 & $14,691.3$ & $18,608.9$ & $18,608.9$ & 1,400 & \\
\hline $60: 40$ & 2.00 & 4.00 & 20.00 & $66,422.6$ & $132,845.1$ & $664,225.5$ & 4,227 & \\
\hline $40: 60$ & 0.03 & 0.05 & 0.05 & 0.0 & 0.0 & 0.0 & 0 & \\
\hline $40: 60$ & 0.10 & 0.10 & 0.10 & 2.4 & 2.4 & 2.4 & 9 & \\
\hline $40: 60$ & 0.50 & 0.50 & 0.50 & 233.6 & 233.6 & 233.6 & 198 & \\
\hline $40: 60$ & 1.50 & 1.90 & 1.90 & 261.0 & 330.6 & 330.6 & 71 & \\
\hline $40: 60$ & 2.00 & 4.00 & 20.00 & $4,069.2$ & $8,138.4$ & $40,692.2$ & 769 & \\
\hline $23: 77$ & 0.01 & 0.03 & 0.03 & 0.0 & 0.0 & 0.0 & 0 & \\
\hline $23: 77$ & 0.03 & 0.05 & 0.05 & 0.0 & 0.0 & 0.0 & 0 & \\
\hline $23: 77$ & 0.10 & 0.10 & 0.10 & 2.6 & 2.6 & 2.6 & 11 & \\
\hline $23: 77$ & 0.50 & 0.50 & 0.50 & 860.4 & 860.4 & 860.4 & 724 & \\
\hline $23: 77$ & 1.50 & 1.90 & 1.90 & $2,912.8$ & $3,689.5$ & $3,689.5$ & 794 & \\
\hline $23: 77$ & 2.00 & 4.00 & 20.00 & 231.1 & 462.2 & $2,311.2$ & 49 & \\
\hline $6: 94$ & 1.00 & 3.00 & 3.00 & $2,936.6$ & $8,809.7$ & $8,809.7$ & 1,930 & \\
\hline $1: 99$ & 0.10 & 1.00 & 1.00 & 3.0 & 30.3 & 30.3 & 169 & \\
\hline $1: 99$ & 1.00 & 20.00 & 20.00 & 644.1 & $12,882.2$ & $12,882.2$ & 1,177 & \\
\hline $1: 99$ & 0.10 & 1.00 & 1.00 & 121.5 & $12,14.9$ & $1,214.9$ & 6,679 & low level \\
\hline $60: 40$ & 0.08 & 0.16 & 0.16 & $19,275.4$ & $38,550.9$ & $3,8550.9$ & 9,215 & low level \\
\hline $60: 40$ & 0.06 & 0.12 & 0.12 & $20,6302.4$ & $412,604.9$ & $412,604.9$ & 134,614 & trace \\
\hline
\end{tabular}


Total volume found:

$\begin{aligned} 523,743 \text { liters (conservative) } & =3,294 \text { barrels } \\ 911,280 \text { liters (aggressive) } & =5,732 \text { barrels } \\ 4,592,215 \text { liters (possible) } & =\quad 28,884 \text { barrels }\end{aligned}$

AVIRIS Run 10: 677 samples x 22,199 scanlines

594,292 pixels mapped out of 15,028,723 total image pixels.

\begin{tabular}{|c|c|c|c|c|c|c|c|c|}
\hline & \multicolumn{3}{|c|}{ Thickness (mm) } & \multicolumn{3}{|c|}{ (liters/pixel) } & \multirow{2}{*}{$\begin{array}{l}\text { Pixels } \\
\text { mapped }\end{array}$} & \\
\hline Oil: H2O & Cons. & Aggr. & POSS & Conserv. & Aggress. & Possible & & \\
\hline $92: 8$ & 0.10 & 0.10 & 0.10 & 338.6 & 338.6 & 338.6 & 52 & \\
\hline $92: 8$ & 0.50 & 0.50 & 20.00 & $1,130.6$ & $1,130.6$ & $45,223.0$ & 88 & \\
\hline $92: 8$ & 1.50 & 1.90 & 20.00 & 939.9 & $1,190.6$ & $12,532.7$ & 28 & \\
\hline $92: 8$ & 2.00 & 4.00 & 20.00 & 61.6 & 123.2 & 616.0 & 1 & \\
\hline $80: 20$ & 1.00 & 1.50 & 20.00 & $69,844.9$ & $104,767.3$ & $1,396,897.1$ & 1,645 & \\
\hline $75: 25$ & 1.50 & 1.50 & 20.00 & $13,511.9$ & $13,511.9$ & $180,158.4$ & 401 & \\
\hline $60: 40$ & 0.01 & 0.03 & 0.03 & 0.4 & 0.9 & 0.9 & 2 & \\
\hline $60: 40$ & 0.03 & 0.05 & 0.05 & 16.7 & 33.3 & 33.3 & 40 & \\
\hline $60: 40$ & 0.10 & 0.10 & 0.10 & 18.5 & 18.5 & 18.5 & 16 & \\
\hline $60: 40$ & 0.50 & 0.50 & 0.50 & $5,279.6$ & $5,279.6$ & $5,279.6$ & 725 & \\
\hline $60: 40$ & 1.50 & 1.90 & 1.90 & $9,521.0$ & $12,060.0$ & $12,060.0$ & 686 & \\
\hline $60: 40$ & 2.00 & 4.00 & 20.00 & $77,244.3$ & $154,488.6$ & $772,443.1$ & 2,718 & \\
\hline $40: 60$ & 0.03 & 0.05 & 0.05 & 0.1 & 0.1 & 0.1 & 1 & \\
\hline $40: 60$ & 0.10 & 0.10 & 0.10 & 0.9 & 0.9 & 0.9 & 3 & \\
\hline $40: 60$ & 0.50 & 0.50 & 0.50 & 82.4 & 82.4 & 82.4 & 59 & \\
\hline $40: 60$ & 1.50 & 1.90 & 1.90 & 115.9 & 146.8 & 146.8 & 27 & \\
\hline $40: 60$ & 2.00 & 4.00 & 20.00 & $2,209.3$ & $4,418.7$ & $22,093.5$ & 337 & \\
\hline $23: 77$ & 0.01 & 0.03 & 0.03 & 0.0 & 0.1 & 0.1 & 1 & \\
\hline $23: 77$ & 0.03 & 0.05 & 0.05 & 0.1 & 0.2 & 0.2 & 1 & \\
\hline $23: 77$ & 0.10 & 0.10 & 0.10 & 1.6 & 1.6 & 1.6 & 6 & \\
\hline $23: 77$ & 0.50 & 0.50 & 0.50 & $2,162.5$ & $21,62.5$ & $2,162.5$ & 1,888 & \\
\hline $23: 77$ & 1.50 & 1.90 & 1.90 & $28,365.6$ & $35,929.7$ & $35,929.7$ & 5,811 & \\
\hline $23: 77$ & 2.00 & 4.00 & 20.00 & $3,465.0$ & $6,929.9$ & $34,649.6$ & 499 & \\
\hline $6: 94$ & 1.00 & 3.00 & 3.00 & $36,899.5$ & $110,698.6$ & $110,698.6$ & 28,424 & \\
\hline $1: 99$ & 0.10 & 1.00 & 1.00 & 3.2 & 32.3 & 32.3 & 133 & \\
\hline $1: 99$ & 1.00 & 20.00 & 20.00 & 539.8 & $10,796.1$ & $10,796.1$ & 989 & \\
\hline $1: 99$ & 0.10 & 1.00 & 1.00 & 695.3 & $6,952.6$ & $6,952.6$ & 37,000 & level \\
\hline $60: 40$ & 0.08 & 0.16 & 0.16 & $18,097.9$ & $36,195.8$ & $3,6195.8$ & 10,802 & low level \\
\hline $60: 40$ & 0.06 & 0.12 & 0.12 & $574,693.2$ & $1,149,386.3$ & $1,149,386.3$ & 501,909 & trace \\
\hline
\end{tabular}

Total volume found:

$\begin{array}{rll}845,240 \text { liters (conservative) } & & 5,316 \text { barrels } \\ 1,656,678 \text { liters (aggressive) } & = & 10,420 \text { barrels } \\ 3,834,731 \text { liters (possible) } & = & 24,119 \text { barrels }\end{array}$

AVIRIS Run 11: 677 samples x 16,835 scanlines 249,214 pixels mapped out of 11,397,295 total image pixels.

\begin{tabular}{|c|c|c|c|c|c|c|c|}
\hline & Thi & kness & $(\mathrm{mm})$ & \multicolumn{3}{|c|}{ (liters/pixel) } & Pixels \\
\hline Oil : H2O & Cons. & $\operatorname{Aggr}$ & $\overline{\text { Poss. }}$ & Conserv. & Aggress. & Possible & \\
\hline $92: 8$ & 0.10 & 0.10 & 0.10 & $1,109.7$ & $1,109.7$ & $1,109.7$ & \\
\hline $92: 8$ & 0.50 & 0.50 & 20.00 & $10,714.7$ & $10,714.7$ & $428,586.0$ & \\
\hline $92: 8$ & 1.50 & 1.90 & 20.00 & $229,802.3$ & $291,082.9$ & $3,064,030.3$ & \\
\hline
\end{tabular}




\begin{tabular}{|c|c|c|c|c|c|c|c|c|}
\hline $92: 8$ & 2.00 & 4.00 & 20.00 & $9,229.2$ & $18,458.4$ & $92,291.9$ & 72 & \\
\hline $80: 20$ & 1.00 & 1.50 & 20.00 & $330,680.6$ & $496,020.9$ & $6,613,611.8$ & 7,861 & \\
\hline $75: 25$ & 1.50 & 1.50 & 20.00 & $28,007.7$ & $28,007.7$ & $373,436.1$ & 855 & \\
\hline $60: 40$ & 0.01 & 0.03 & 0.03 & 2.2 & 4.5 & 4.5 & 9 & \\
\hline $60: 40$ & 0.03 & 0.05 & 0.05 & 47.5 & 95.0 & 95.0 & 125 & \\
\hline $60: 40$ & 0.10 & 0.10 & 0.10 & 69.2 & 69.2 & 69.2 & 65 & \\
\hline $60: 40$ & 0.50 & 0.50 & 0.50 & $14,560.4$ & $14,560.4$ & $14,560.4$ & 2,062 & \\
\hline $60: 40$ & 1.50 & 1.90 & 1.90 & $37,030.2$ & $46,904.9$ & $46,904.9$ & 2,882 & \\
\hline $60: 40$ & 2.00 & 4.00 & 20.00 & $122,918.2$ & $245,836.4$ & $1,229,182.2$ & 5,027 & \\
\hline $40: 60$ & 0.03 & 0.05 & 0.05 & 0.0 & 0.0 & 0.0 & 0 & \\
\hline $40: 60$ & 0.10 & 0.10 & 0.10 & 2.1 & 2.1 & 2.1 & 8 & \\
\hline $40: 60$ & 0.50 & 0.50 & 0.50 & 288.5 & 288.5 & 288.5 & 208 & \\
\hline $40: 60$ & 1.50 & 1.90 & 1.90 & 875.5 & $1,108.9$ & $1,108.9$ & 150 & \\
\hline $40: 60$ & 2.00 & 4.00 & 20.00 & $5,926.9$ & $11,853.8$ & $5,9268.8$ & 822 & \\
\hline $23: 77$ & 0.01 & 0.03 & 0.03 & 0.2 & 0.3 & 0.3 & 3 & \\
\hline $23: 77$ & 0.03 & 0.05 & 0.05 & 0.4 & 0.9 & 0.9 & 7 & \\
\hline $23: 77$ & 0.10 & 0.10 & 0.10 & 6.2 & 6.2 & 6.2 & 23 & \\
\hline $23: 77$ & 0.50 & 0.50 & 0.50 & $4,505.3$ & $4,505.3$ & $4,505.3$ & 3,613 & \\
\hline $23: 77$ & 1.50 & 1.90 & 1.90 & $12,498.6$ & $15,831.5$ & $15,831.5$ & 2,865 & \\
\hline $23: 77$ & 2.00 & 4.00 & 20.00 & $2,649.6$ & $5,299.2$ & $26,495.8$ & 450 & \\
\hline $6: 94$ & 1.00 & 3.00 & 3.00 & $3,311.4$ & $9,934.2$ & $9,934.2$ & 3,036 & \\
\hline $1: 99$ & 0.10 & 1.00 & 1.00 & 2.4 & 24.0 & 24.0 & 170 & \\
\hline $1: 99$ & 1.00 & 20.00 & 20.00 & 284.5 & $5,690.9$ & $5,690.9$ & 720 & \\
\hline $1: 99$ & 0.10 & 1.00 & 1.00 & 110.1 & $1,101.1$ & $1,101.1$ & 6,948 & low level \\
\hline $60: 40$ & 0.08 & 0.16 & 0.16 & $34,050.3$ & $68,100.7$ & $68,100.7$ & 19,295 & low level \\
\hline $60: 40$ & 0.06 & 0.12 & 0.12 & $295,113.0$ & $590,226.1$ & $590,226.1$ & 188,691 & trace \\
\hline
\end{tabular}

Total volume found:

$1,143,797$ liters (conservative) =

$1,866,838$ liters (aggressive)=

$12,646,467$ liters (possible) =
7,194 barrels

11,742 barrels

79,543 barrels

AVIRIS Run 14: 677 samples x 22,933 scanlines

222,826 pixels mapped out of 15,525,641 total image pixels.

\begin{tabular}{|c|c|c|c|}
\hline & \multicolumn{2}{|c|}{ Thickness } & $(\mathrm{mm})$ \\
\hline Oil:H2O & Cons. & $\operatorname{Aggr}$ & Poss. \\
\hline $92: 8$ & 0.10 & 0.10 & 0.10 \\
\hline $92: 8$ & 0.50 & 0.50 & 20.00 \\
\hline $92: 8$ & 1.50 & 1.90 & 20.00 \\
\hline $92: 8$ & 2.00 & 4.00 & 20.00 \\
\hline $75: 25$ & 1.50 & 1.50 & 20.00 \\
\hline $80: 20$ & 1.00 & 1.50 & 20.00 \\
\hline $60: 40$ & 0.01 & 0.03 & 0.03 \\
\hline $60: 40$ & 0.03 & 0.05 & 0.05 \\
\hline $60: 40$ & 0.10 & 0.10 & 0.10 \\
\hline $60: 40$ & 0.50 & 0.50 & 0.50 \\
\hline $60: 40$ & 1.50 & 1.90 & 1.90 \\
\hline $60: 40$ & 2.00 & 4.00 & 20.00 \\
\hline $40: 60$ & 0.01 & 0.03 & 0.03 \\
\hline $40: 60$ & 0.03 & 0.05 & 0.05 \\
\hline $40: 60$ & 0.10 & 0.10 & 0.10 \\
\hline $40: 60$ & 0.50 & 0.50 & 0.50 \\
\hline $40: 60$ & 1.50 & 1.90 & 1.90 \\
\hline $40: 60$ & 2.00 & 4.00 & 20.00 \\
\hline
\end{tabular}

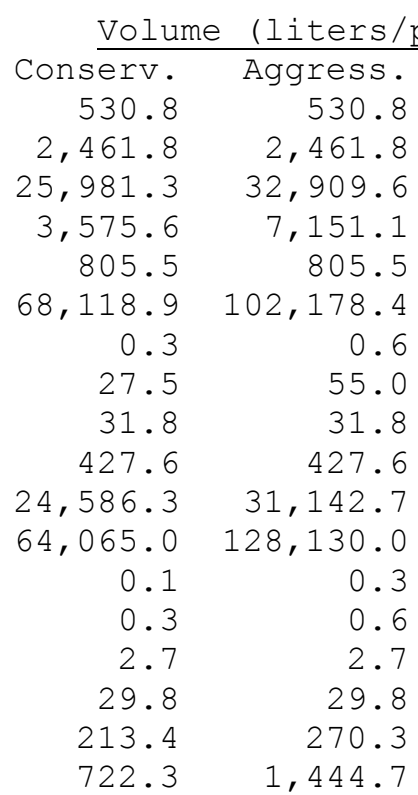

Pixels
mapped
80.0
147.0
500.0
44.0
30.0
$2,061.0$
1.0
39.0
18.0
100.0
256.0
249.0
1.0
1.0
3.0
16.0
32.0
77.0

Possible 530.8 $98,471.8$ $346,417.3$ $35,755.6$ $10,739.8$ $1,362,378.6$ 0.6 55.0 31.8 427.6 $31,142.7$ $640,650.2$ 0.3 0.6 2.7 29.8 270.3 $7,223.3$ 


\begin{tabular}{|c|c|c|c|c|c|c|c|c|}
\hline $23: 77$ & 0.01 & 0.03 & 0.03 & 0.3 & 0.7 & 0.7 & 3.0 & \\
\hline $23: 77$ & 0.03 & 0.05 & 0.05 & 0.1 & 0.2 & 0.2 & 1.0 & \\
\hline $23: 77$ & 0.10 & 0.10 & 0.10 & 0.3 & 0.3 & 0.3 & 1.0 & \\
\hline $23: 77$ & 0.50 & 0.50 & 0.50 & $3,523.4$ & $3,523.4$ & $3,523.4$ & $1,721.0$ & \\
\hline $23: 77$ & 1.50 & 1.90 & 1.90 & $32,674.1$ & $41,387.2$ & $41,387.2$ & $4,931.0$ & \\
\hline $23: 77$ & 2.00 & 4.00 & 20.00 & $8,444.1$ & $16,888.3$ & $84,441.3$ & $1,018.0$ & \\
\hline $5: 94$ & 1.00 & 3.00 & 3.00 & $22,123.5$ & $66,370.4$ & $66,370.4$ & $14,901.0$ & \\
\hline $1: 98$ & 0.10 & 1.00 & 1.00 & 7.8 & 77.6 & 77.6 & 428.0 & \\
\hline $1: 98$ & 1.00 & 20.00 & 20.00 & $19,23.2$ & $38,464.6$ & $38,464.6$ & $4,482.0$ & \\
\hline $1: 98$ & 0.10 & 1.00 & 1.00 & 280.5 & $2,805.0$ & $2,805.0$ & $11,914.0$ & low level \\
\hline$: 40$ & 0.08 & 0.16 & 0.16 & $16,037.4$ & $32,074.8$ & $32,074.8$ & $9,444.0$ & low level \\
\hline$: 40$ & 0.06 & 0.12 & 0.12 & $218,250.4$ & $436,500.9$ & $436,500.9$ & $167,027.0$ & trace \\
\hline
\end{tabular}

Total volume found:

$\begin{array}{rlr}494846 \text { liters }(\text { conservative) } & =\quad 3,112 \text { barrels } \\ 945667 \text { liters (aggressive) } & = & 5,948 \text { barrels } \\ 3239775 \text { liters (possible) } & = & 20,377 \text { barrels }\end{array}$




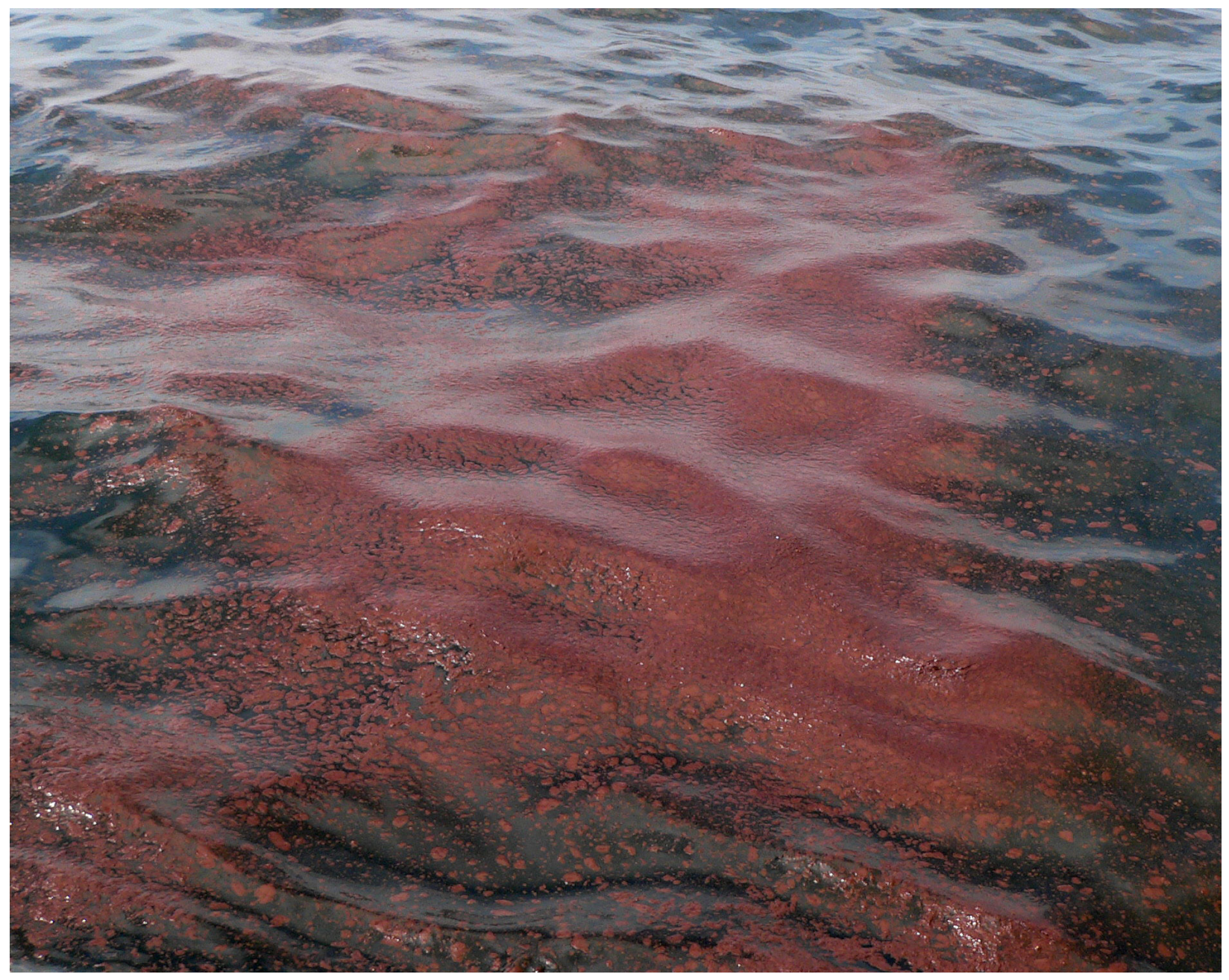

Figure 1a. Image of oil emulsion from the Deepwater Horizon oil spill in the Gulf of Mexico off the Louisiana coast. Photograph taken on May 7, 2010, by Sonia Gallegos/ Gregg Swayze. 


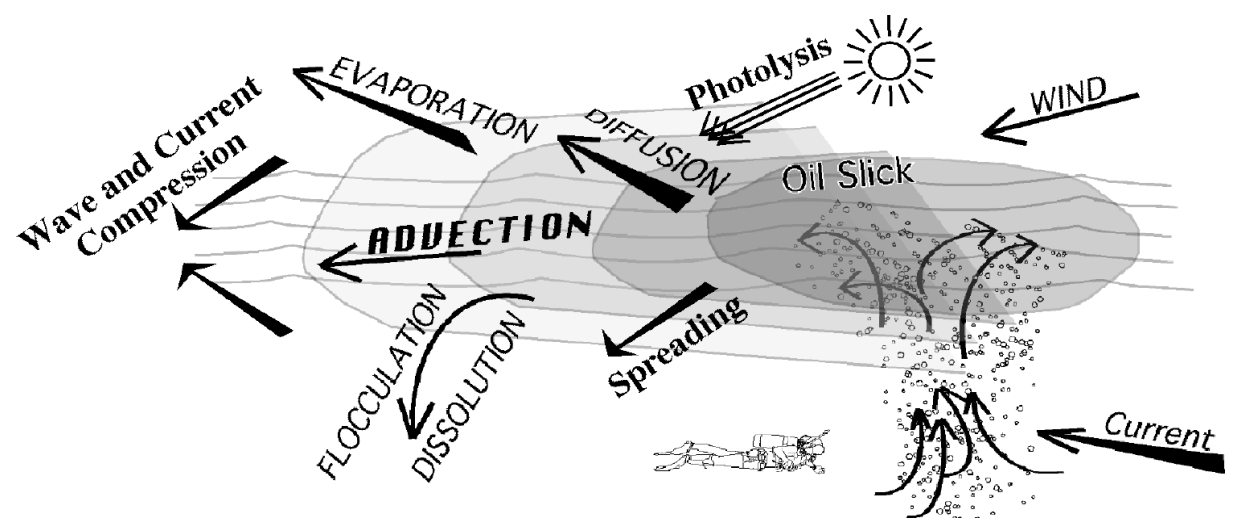

Figure 1b. Major processes affecting oil spills during the initial period after the spill. After Leifer and others (2006). 


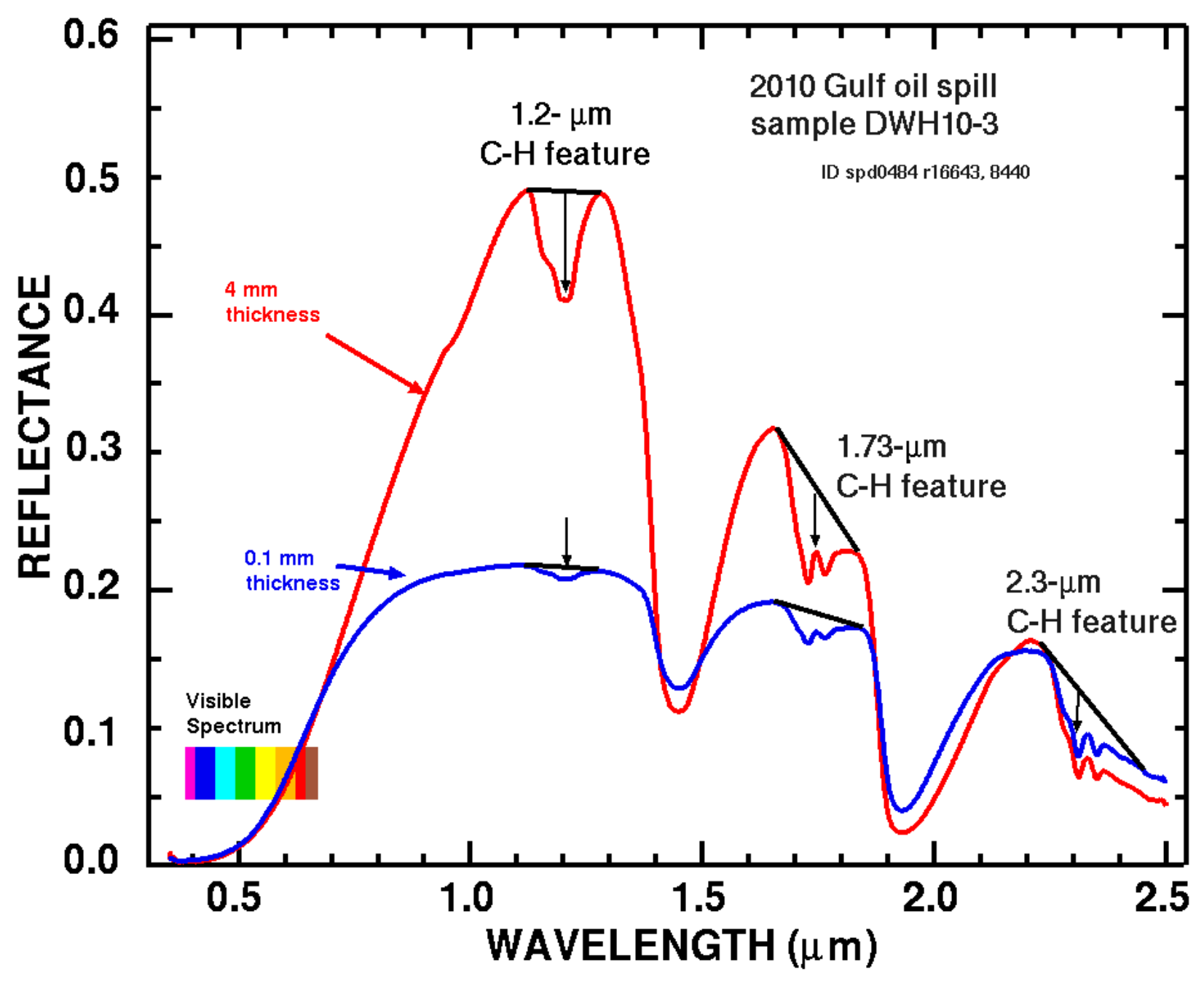

Figure 2. Laboratory spectra of oil emulsion from the Deepwater Horizon oil spill. Sample collected May 7,2010 . At visible wavelengths, the oil is very absorbing and does not change color significantly with thickness. At infrared wavelengths, both reflectance levels and absorptions due to organic compounds vary in strength with thickness. This sample contains approximately 40 percent water as determined by heat separation. Controlled sample thicknesses were created in a cell on a quartz glass window placed over a black substrate and a water substrate. The reflectance was measured over each of these substrates (no difference was observed). Black line is for illustrative purposes to better visualize continuum endpoints. Modified from Clark and others (2010) with a corrections for the blue spectrum. 


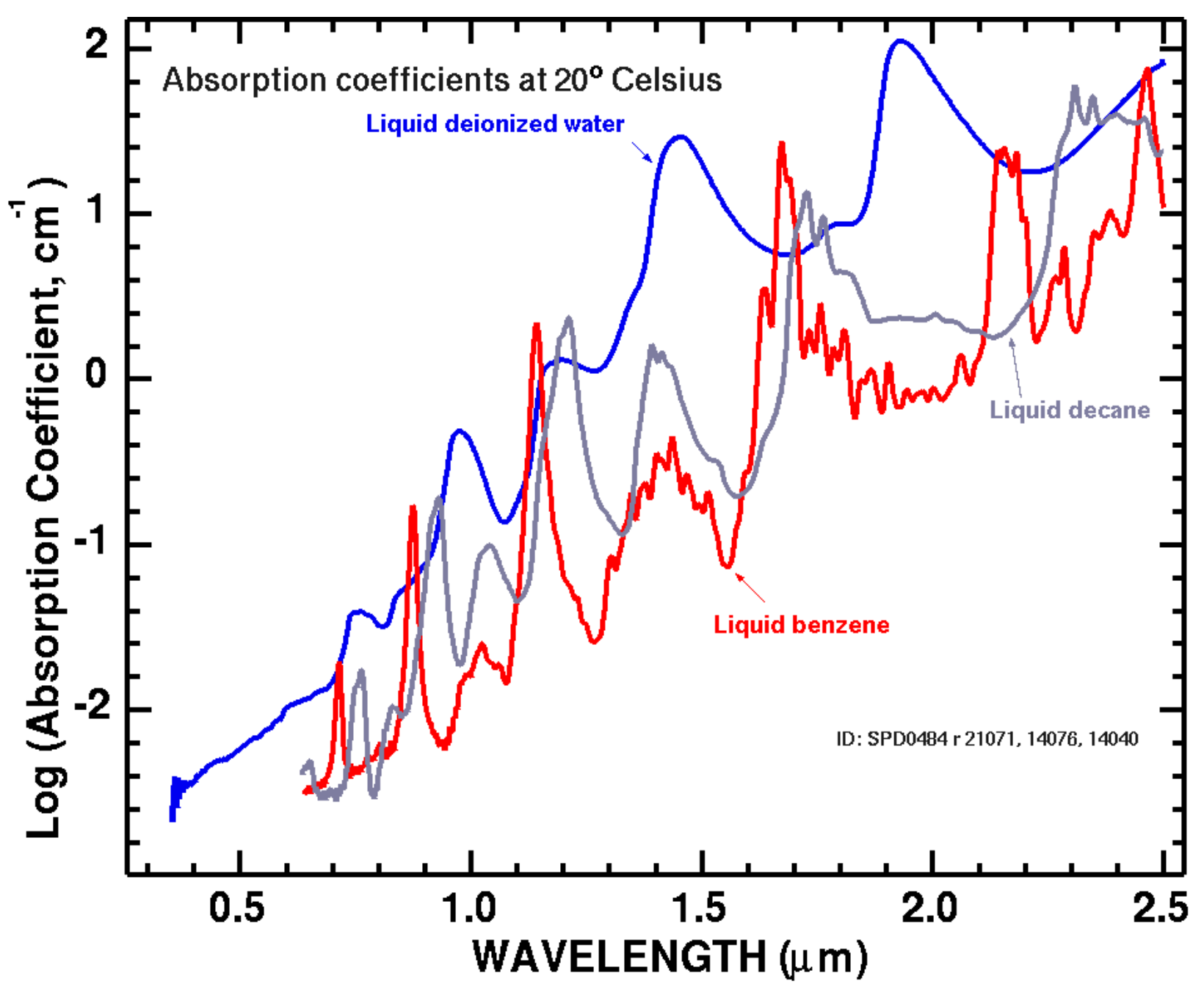

Figure 3a. Absorption coefficients for liquid water, decane, and benzene. Decane is an alkane found in oil. Benzene is an aromatic hydrocarbon present in some oil. An absorption coefficient of $1.0(\log =$ 0 ) absorbs $1 / e$ or 36.8 percent of the light over a 1 centimeter path. The varying absorption strengths displayed in these spectra allow probing to different depths below a surface composed of these materials. 


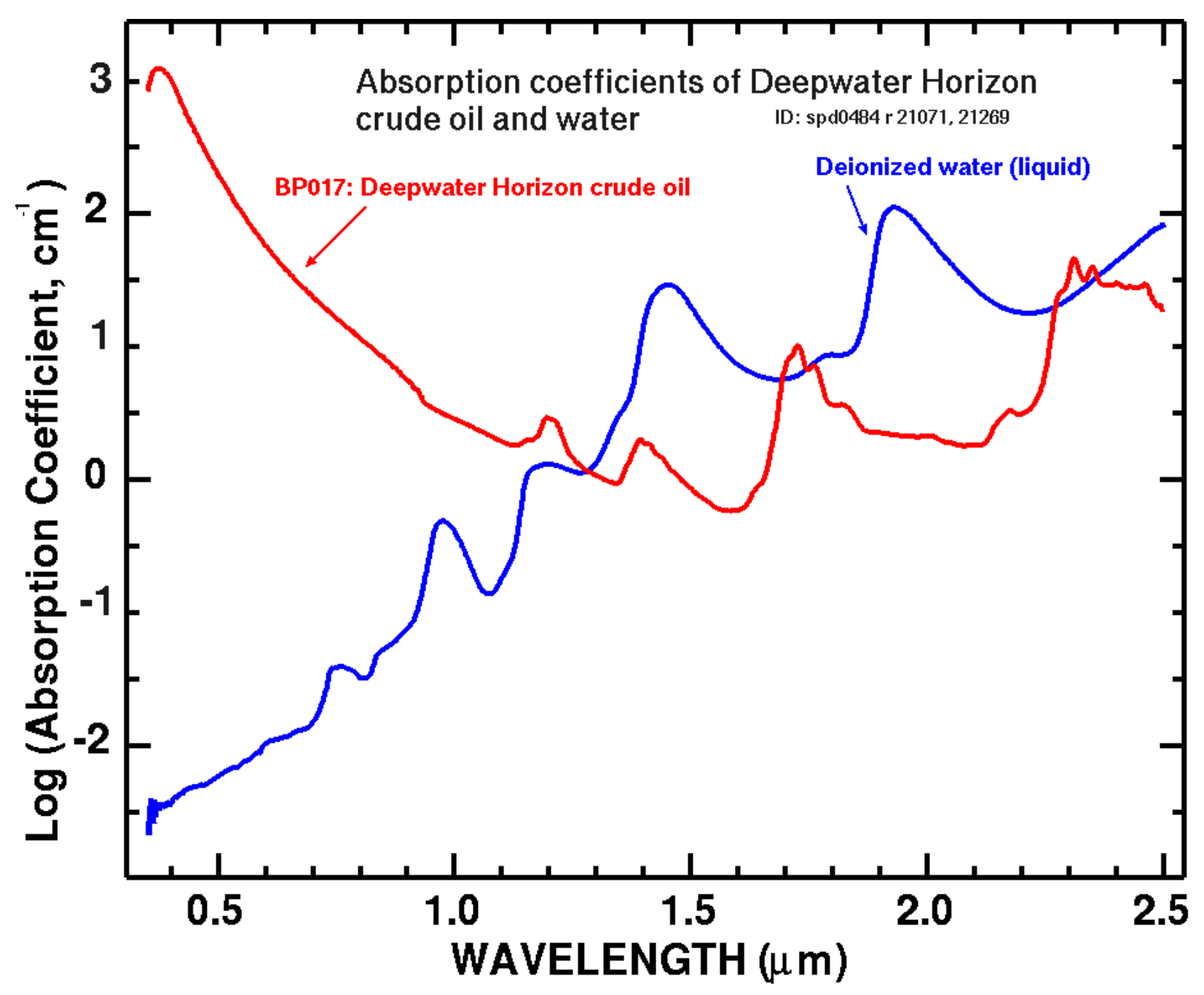

Figure 3b. Absorption coefficients for liquid water, and BP crude oil from the Deepwater Horizon well. The absorptions in the oil (peaks in absorption coefficient) near 1.7 and $2.3 \mu \mathrm{m}$ are due to alkanes, decane, and higher. The strong absorption in the UV is due to asphaltines and gives the oil and oil emulsions the red and orange colors. 

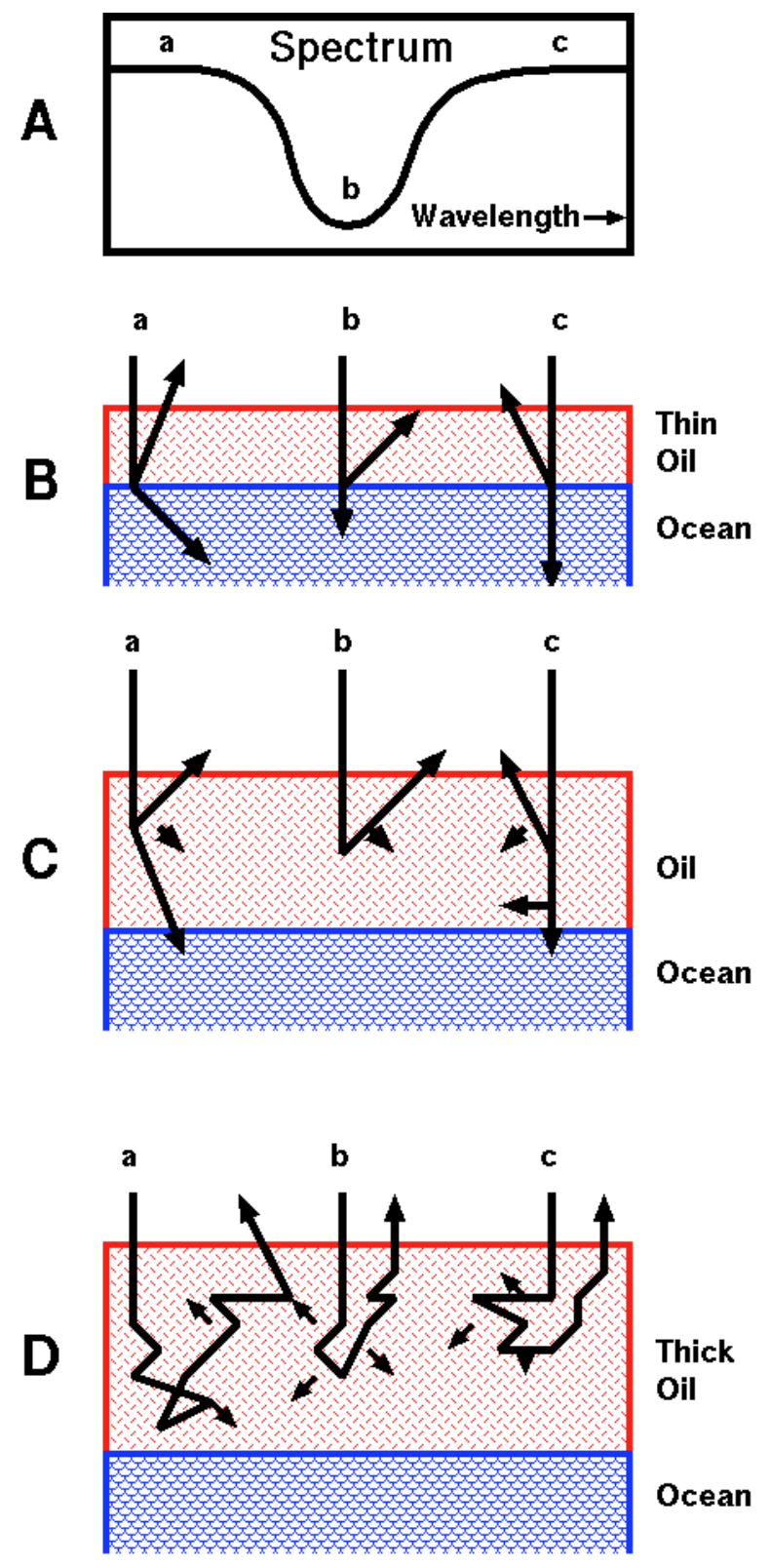

Figure 4. Illustration of how light scatters in oil on water. (A) Example spectrum with three wavelengths labeled $a, b$, and $c$. For thin oil, light with wavelengths both in and out of absorption bands penetrate through the oil (B). For thicker oil (C), light at wavelengths in absorption bands is absorbed before it penetrates very deeply $(C$, wavelength $b)$. At less absorbing wavelengths, light penetrates deeper $(C$, wavelengths $a, c)$. If the oil layer is thin, light at some wavelengths will penetrate into the water $(B$, all wavelengths: $\mathrm{C}$, wavelengths $\mathrm{a}, \mathrm{c}$ ). At infrared wavelengths, light that enters the water is mostly absorbed because of the combination of water's relatively strong absorption coefficient and relatively low density of scattering centers. The oil's thickness, spectral absorption features, and light scattering all contribute to the observed absorption band shapes and their depth in reflectance spectra of such surfaces. If the oil is very thick (D), the total thickness is not probed at any wavelength-a, $b$, or $c$. 


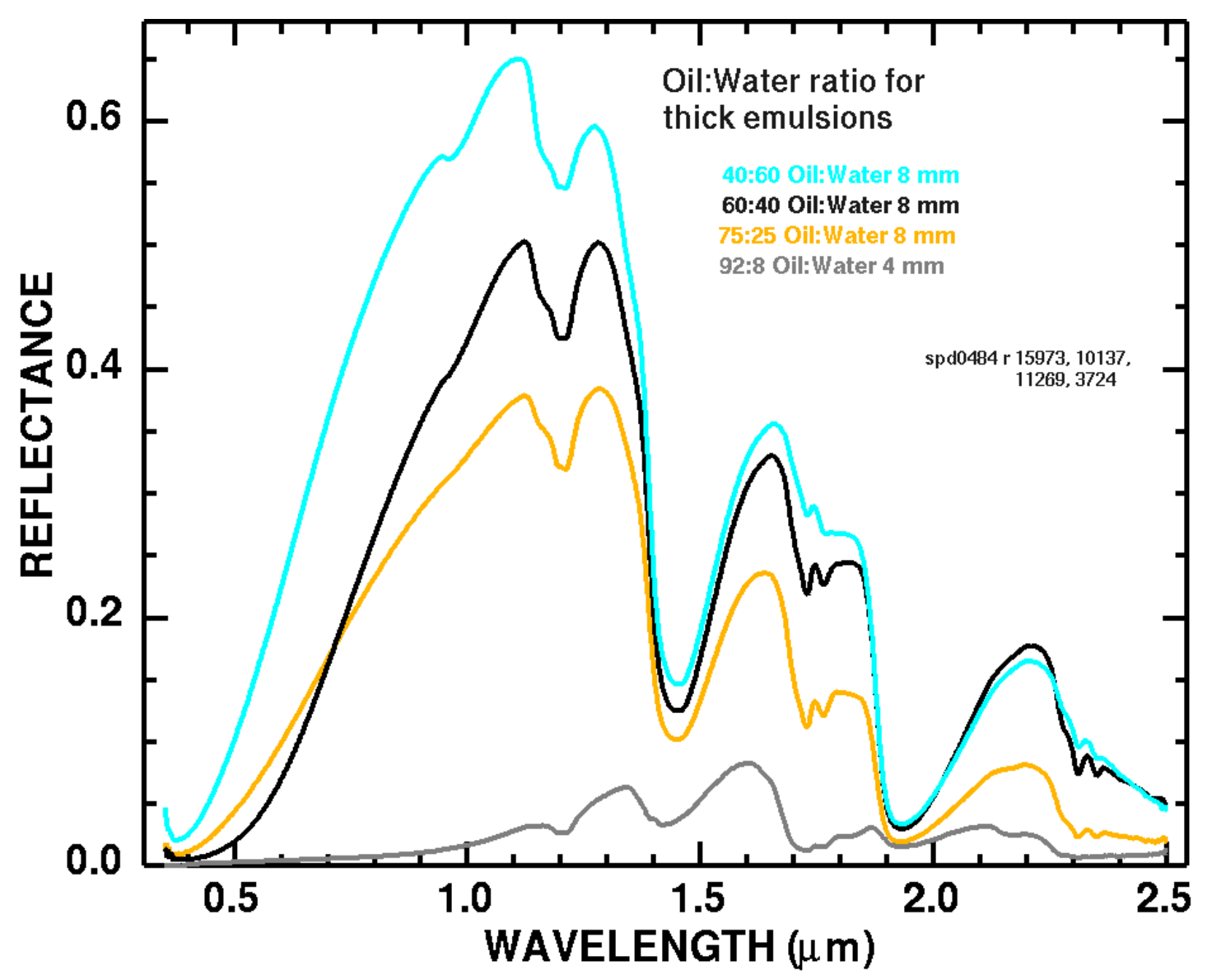

Figure 5a. Reflectance spectra of optically thick oil emulsions with high oil content. Note that among the samples studied here, the 40:60 oil:water has the highest reflectance. 


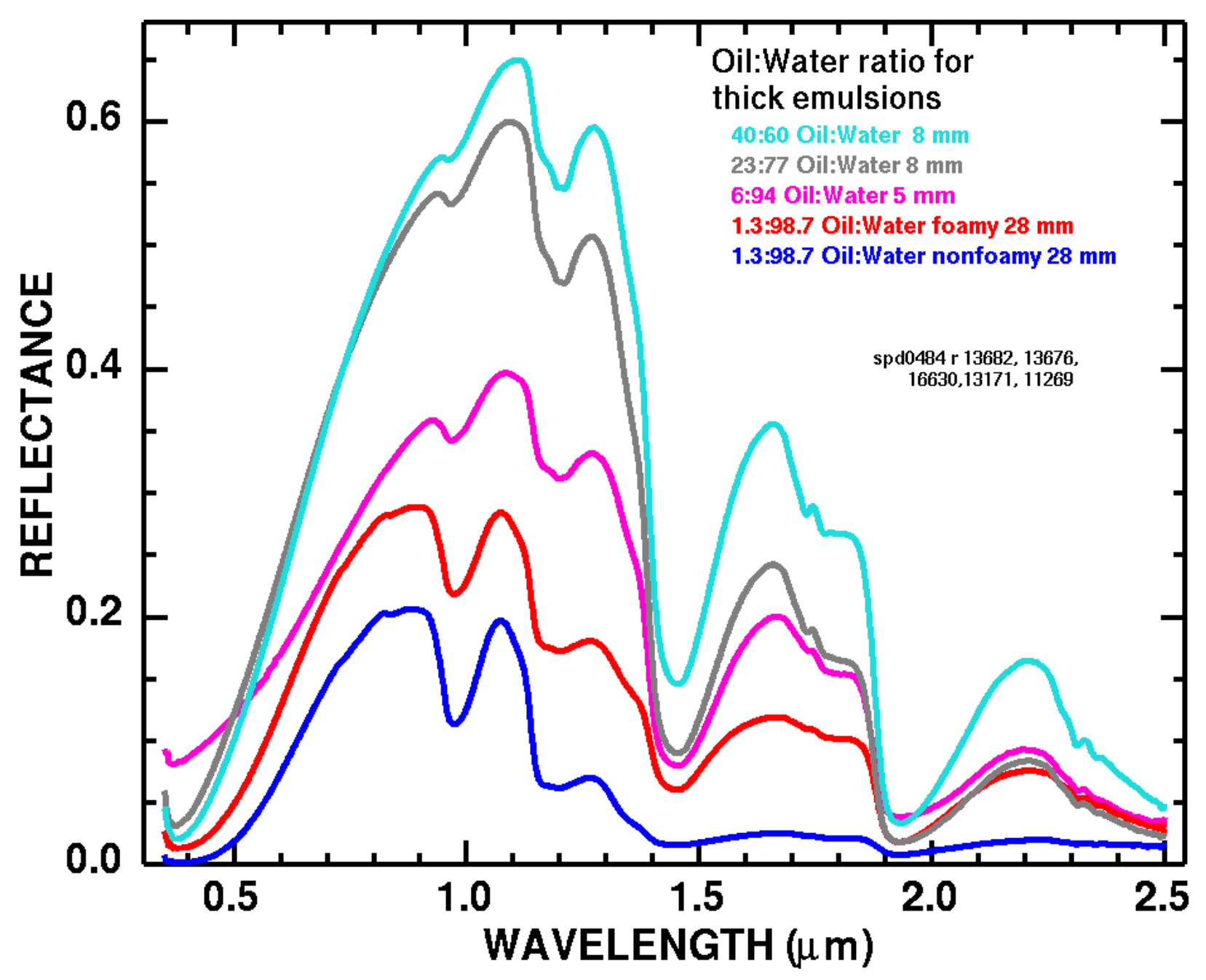

Figure 5b. Reflectance spectra of oil emulsions with low oil content. 


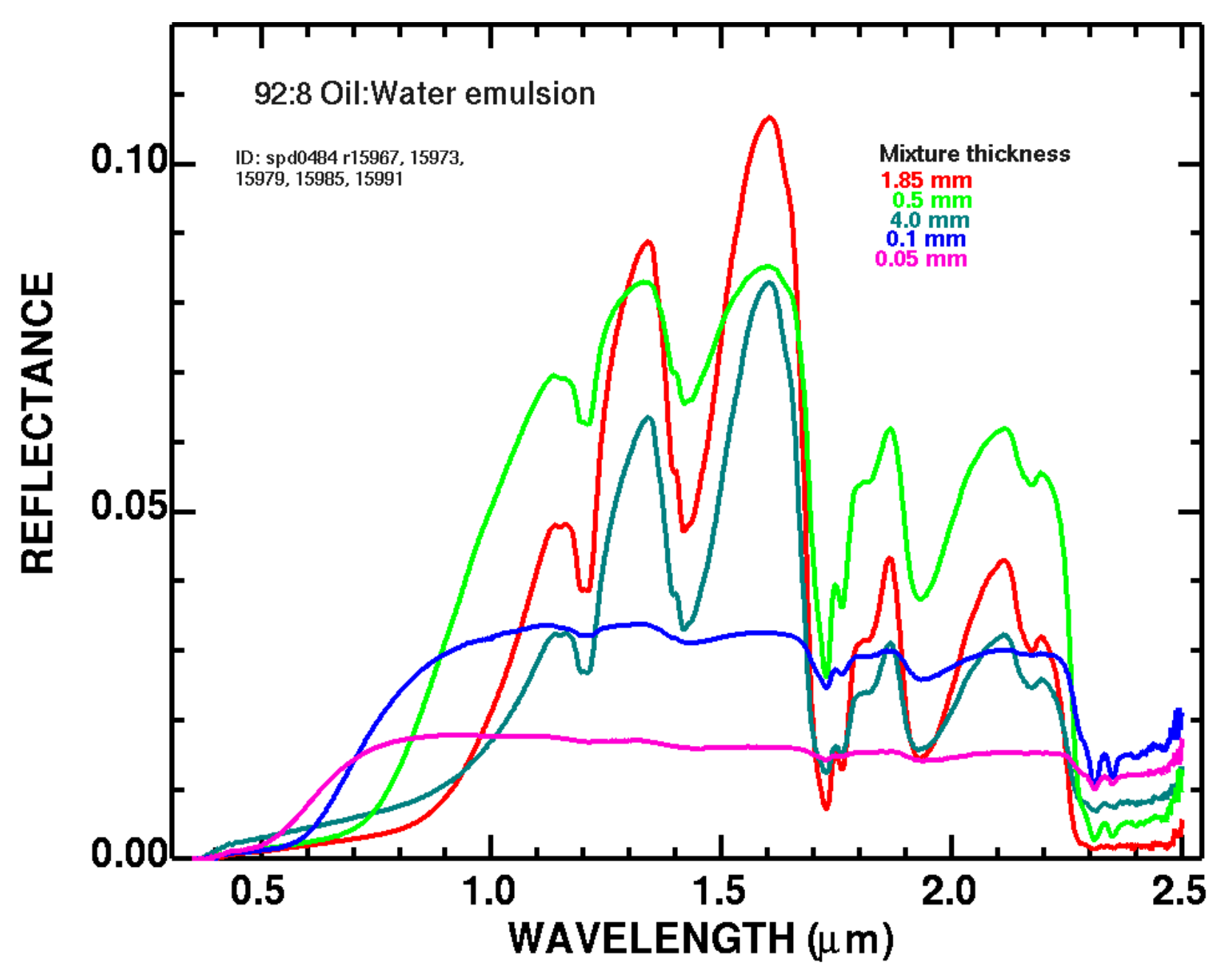

Figure 6a. Reflectance spectra of a 92:08, oil:water emulsion for a range of thicknesses. Note that the high-oil-content spectra shown here vary in color with thickness while the color of higher water content oil emulsions (figures 6a-6d) change little in color with thickness. 


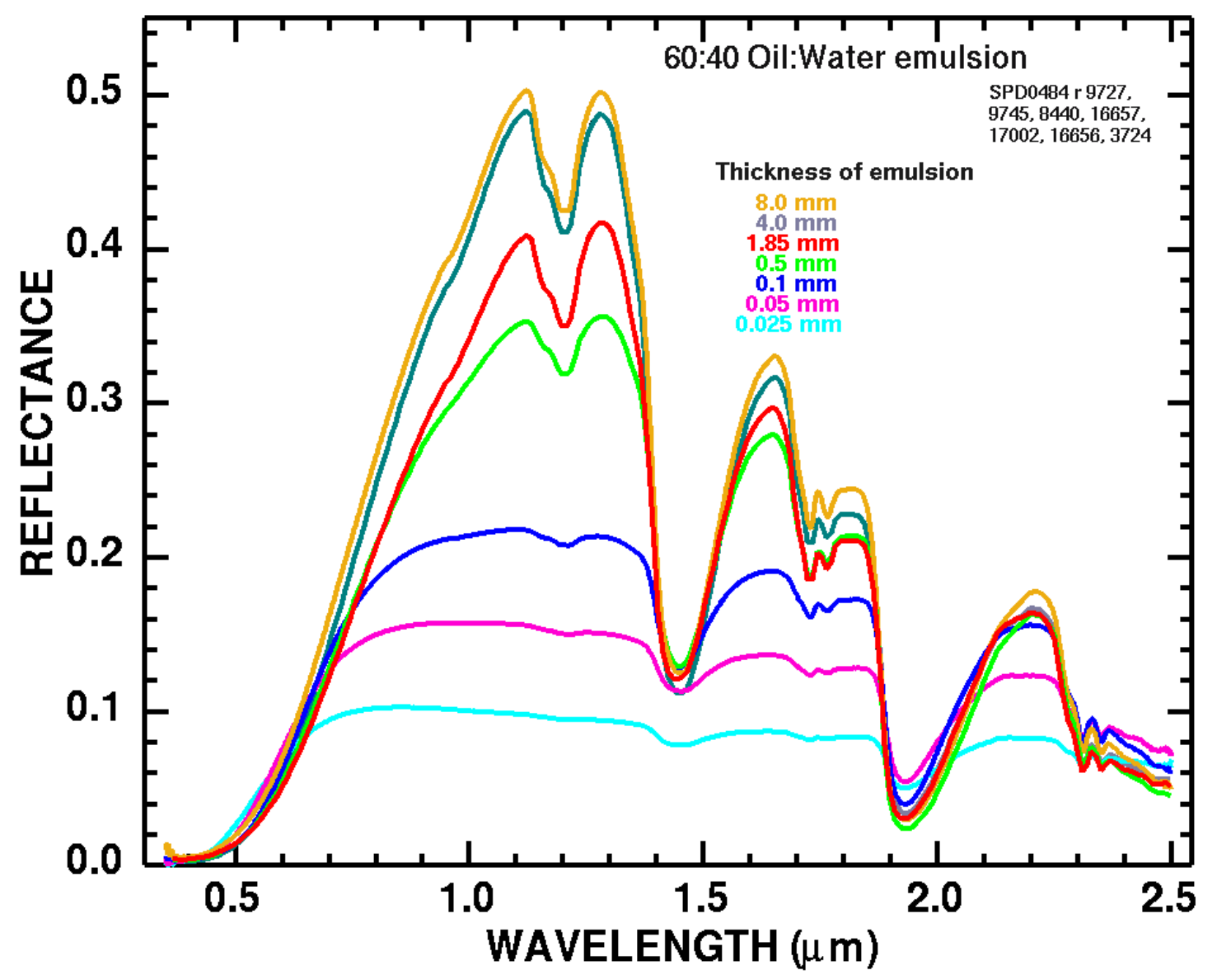

Figure $6 \mathbf{b}$. Reflectance spectra of 60:40, oil:water emulsion for a range of thicknesses. 


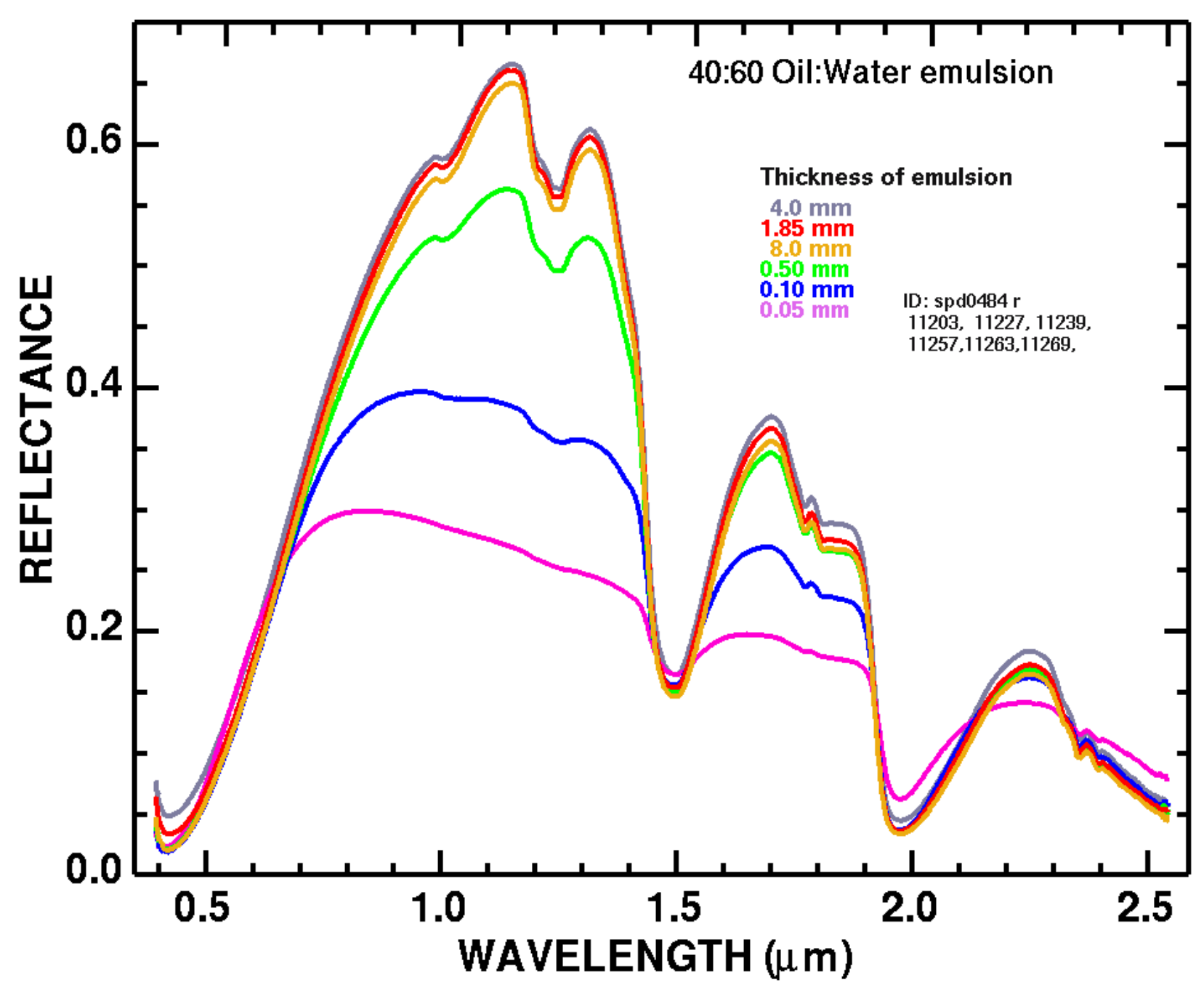

Figure 6c. Reflectance spectra of 40:60, oil:water emulsion for a range of thicknesses. 


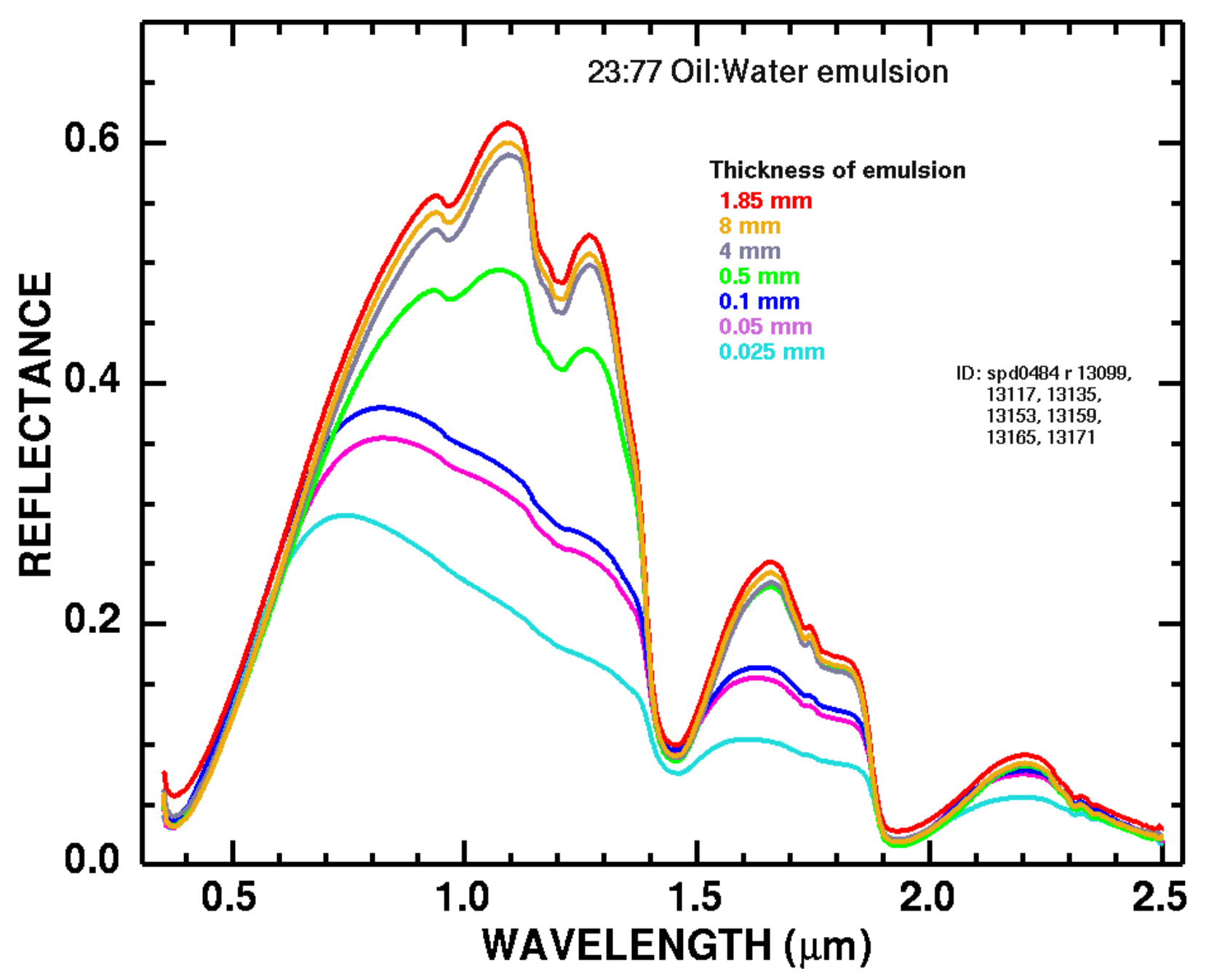

Figure $6 \mathrm{~d}$. Reflectance spectra of a 23:77, oil:water emulsion for a range of thicknesses. 


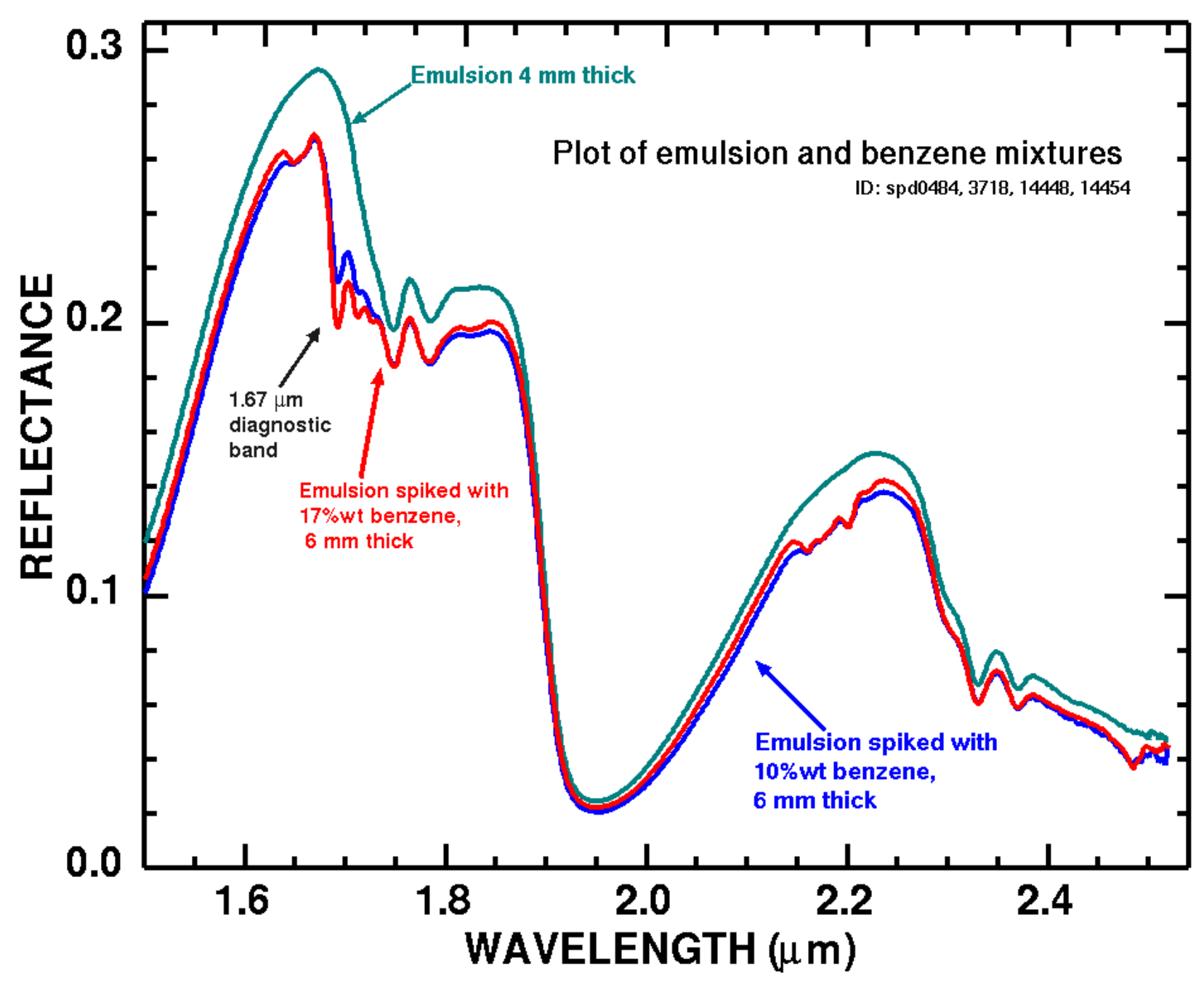

Figure 6e. Absorption features of the aromatic hydrocarbon benzene in a water in oil emulsion. 


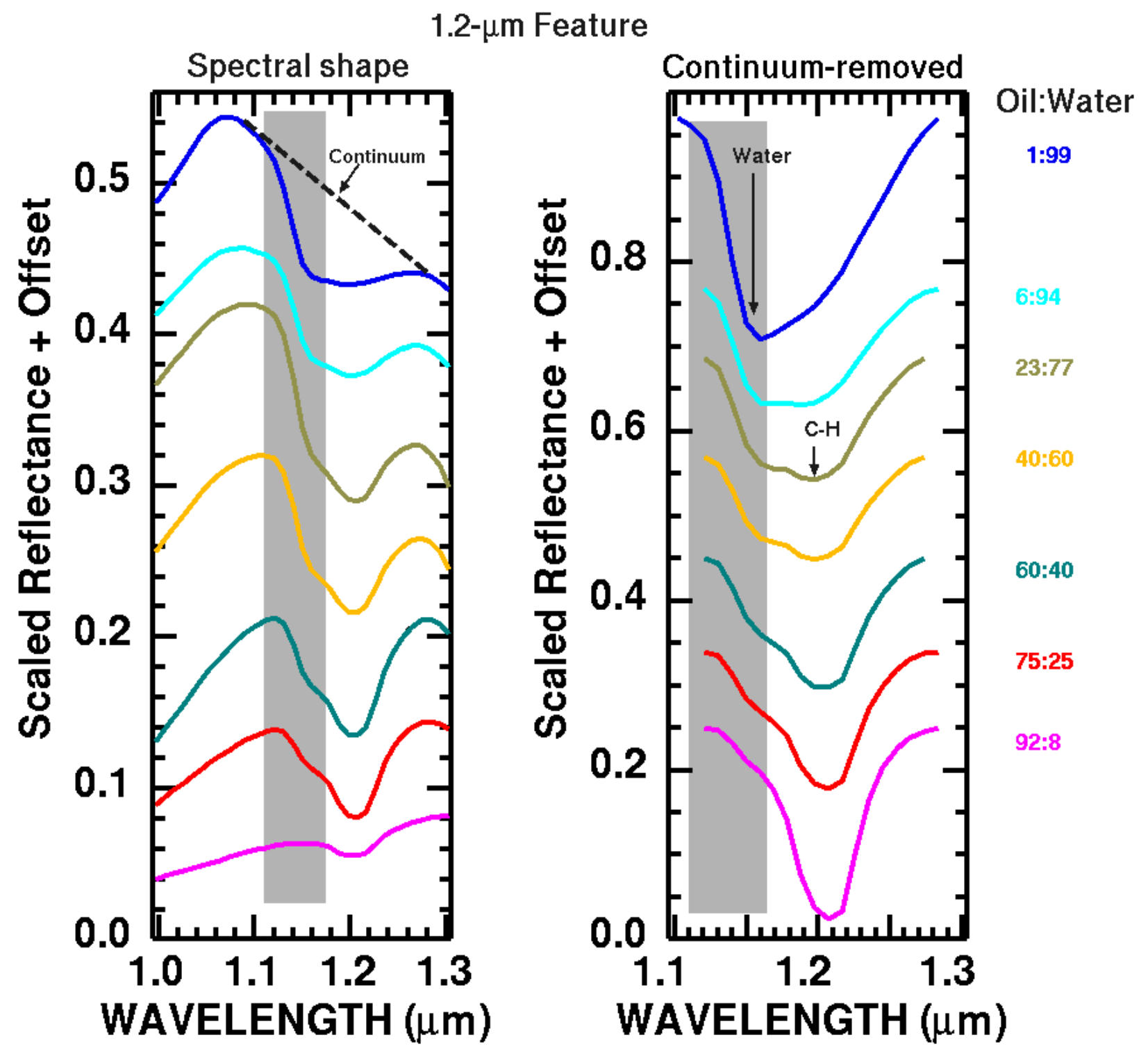

Figure 7a. Changing spectral shape with oil-to-water ratio for the 1.2- $\mu \mathrm{m}$ absorption feature. A straightline continuum is used to produce the curves on the right. The continuum-removal is by division in reflectance. Gray-shaded wavelengths cover portions of spectra where atmospheric water absorbs too much light for analysis of the surface in the May 17, 2010 AVIRIS data. 


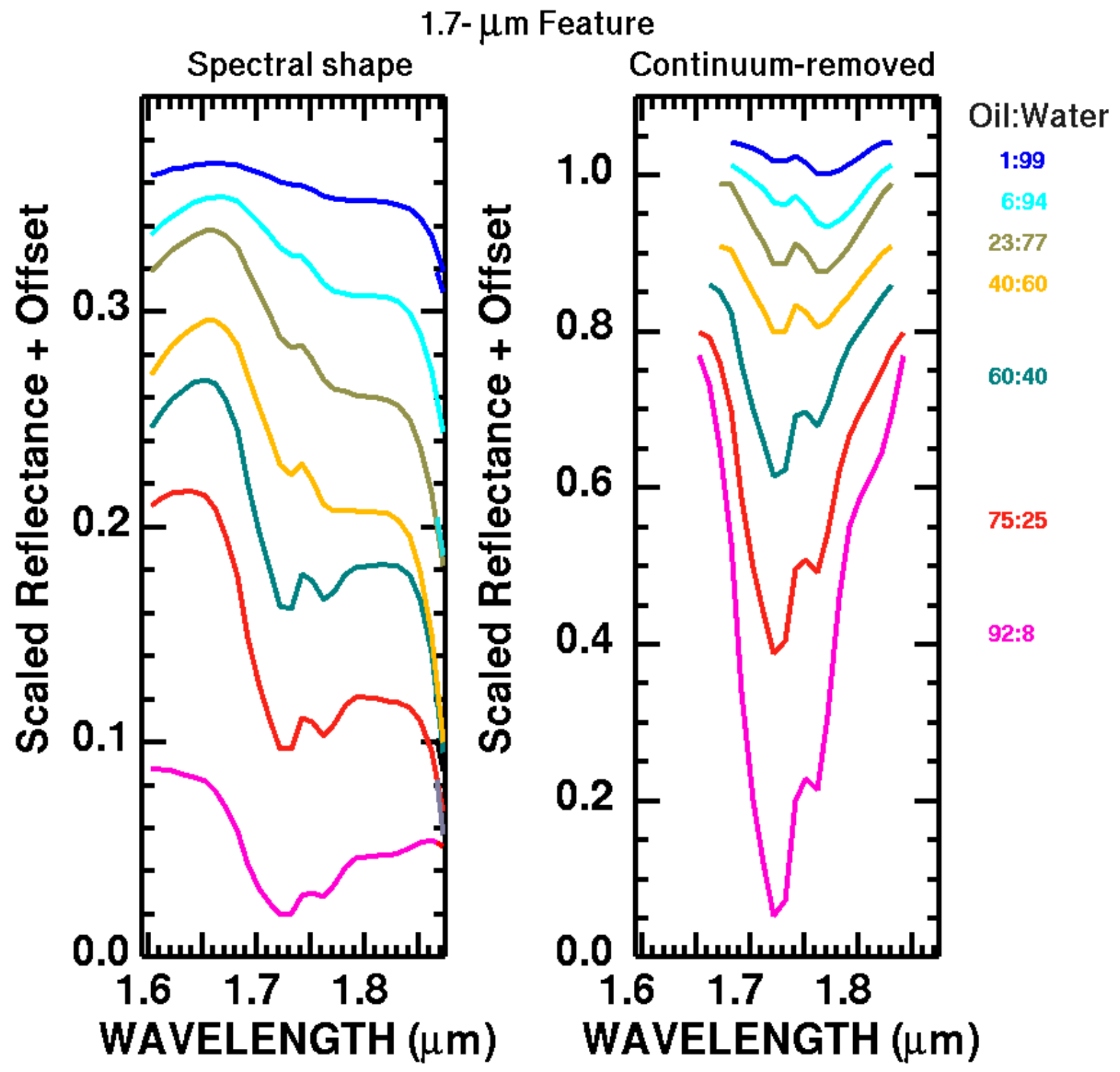

Figure $7 \mathrm{~b}$. Reflectance spectra of the changing spectral shape with oil-to-water ratio for the 1.7- $\mu \mathrm{m}$ absorption feature. Spectra are from those in figures 5 and 6 . A straight-line continuum (as illustrated in figures 2 and 7 a) was used to produce the curves on the right. The continuum-removal is by division in reflectance. 


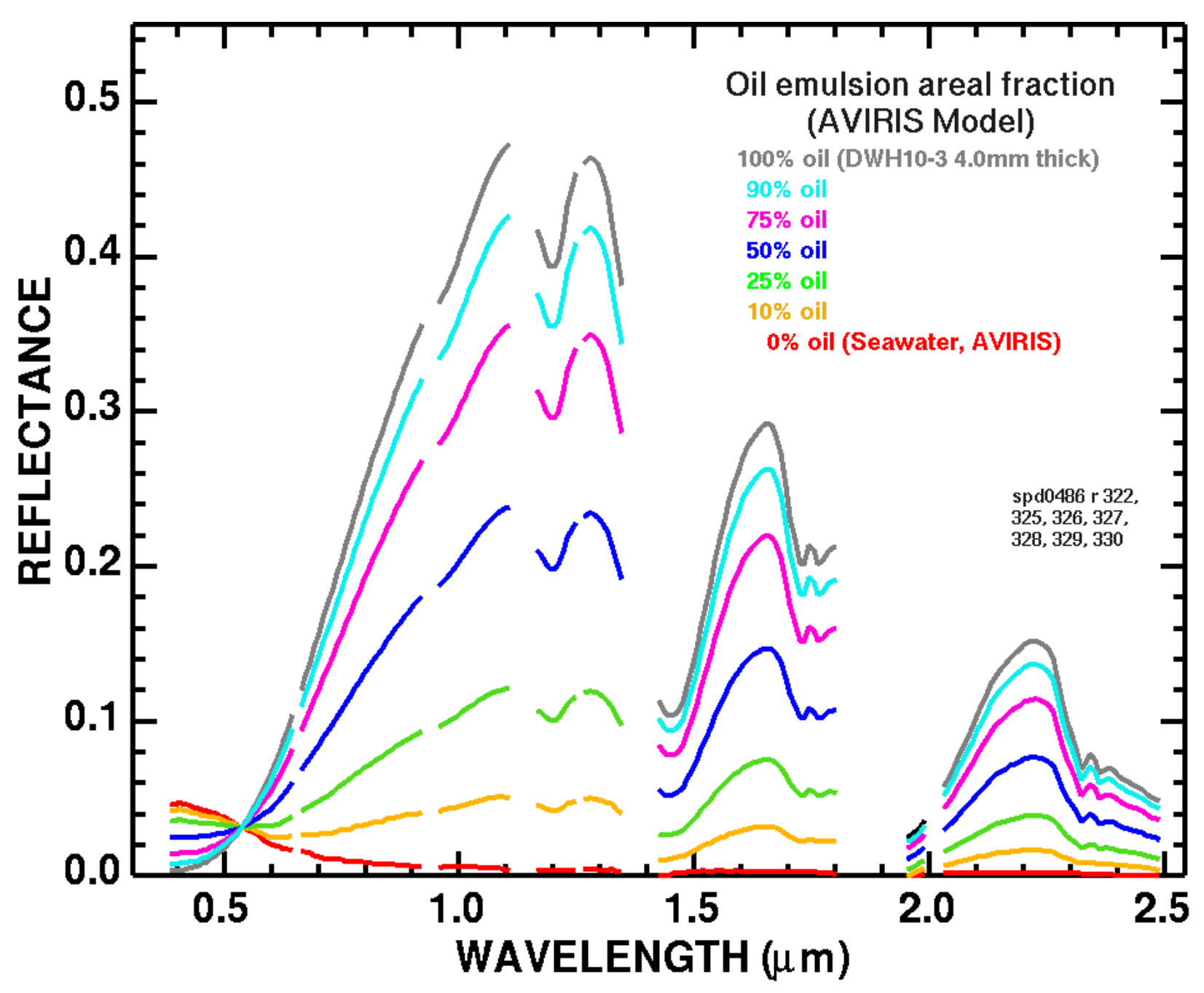

Figure 8. Areal mixture effects of sub-pixel patches of oil and water. Gaps in the spectra are locations where the terrestrial atmosphere absorbs too much light for analysis of the surface reflectance. The (red) lowest (at NIR wavelengths) spectrum is a typical AVIRIS spectrum of open ocean with no detectable oil (including sheen). The rise at short wavelengths (of the red spectrum) is due to light scattered by small particles and by reflected light from the blue sky (Rayleigh scattering). At infrared wavelengths, greater than about $0.9 \mu \mathrm{m}$, the ocean reflectance is very dark, less than 0.1 percent. When oil patches fill less than a full pixel, the mixing effect in the infrared where the oil's organic absorption bands occur has the effect of reducing the reflectance level without changing the shape or depth of the absorption features. 


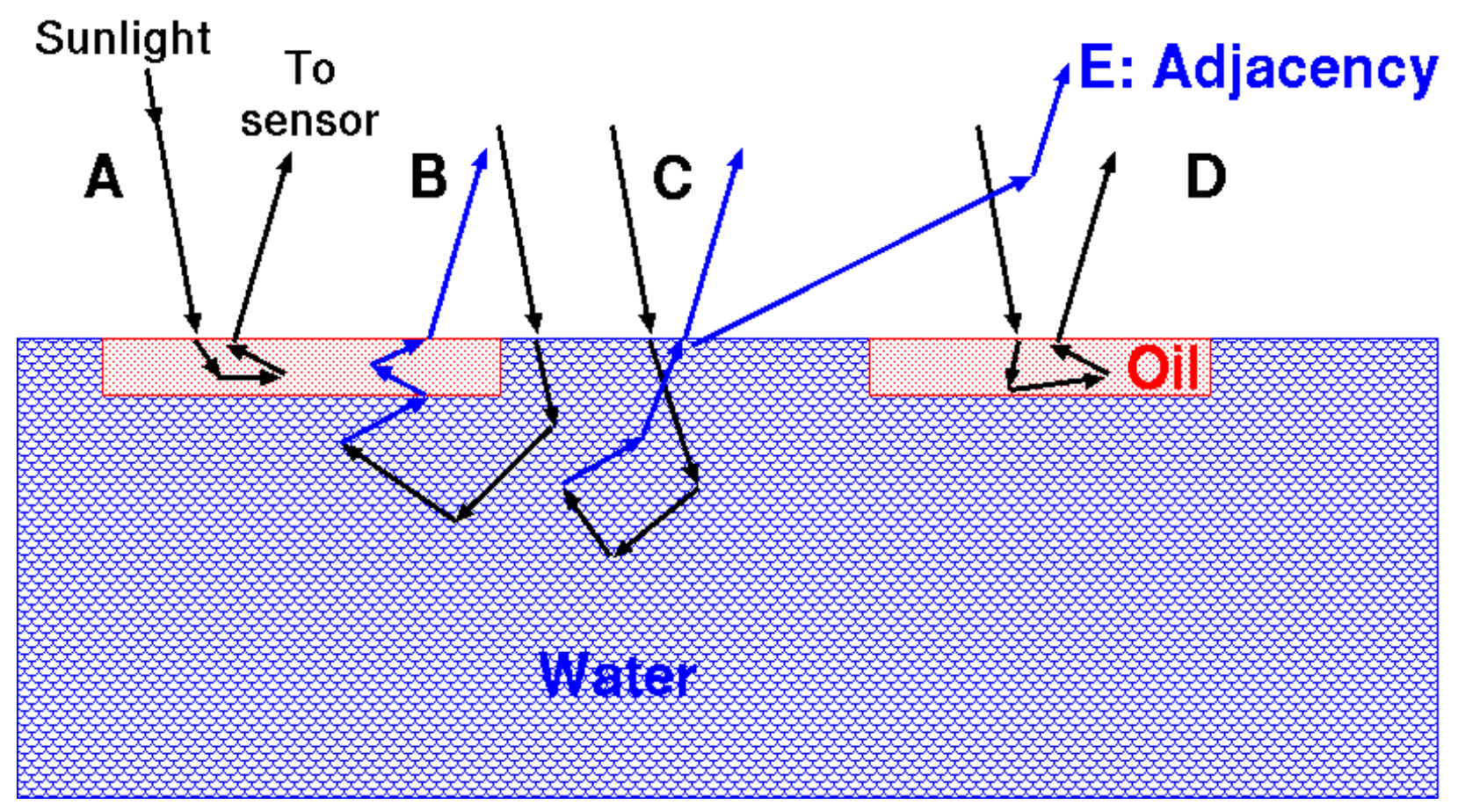

Figure 9. Illustration of light-scattering effects of oil in water. (A) Light scattered to the sensor through the oil. (B) Light transmitted and scattered through water then through the oil and to the sensor. This scattered light component may be significant in thin patches of oil and oil sheen. (C) Light scattered from the ocean. (D) Same as (A), but including light scattered by aerosols (E) adding to the signal from the oil. Adjacency effects $(E)$ will be minimal in the infrared and an increasing problem at shorter wavelengths. Adjacency effects will increase near burning fires whose aerosols can also affect NIR wavelengths. 


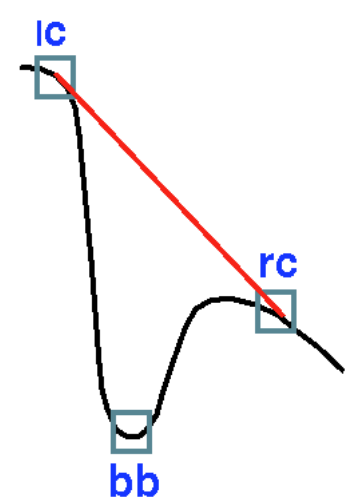

LS $>1$ $0<R S<1$

\section{Shoulderness}

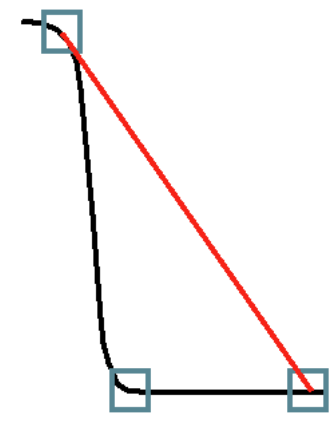

LS = infinity $\mathrm{RS}=0$

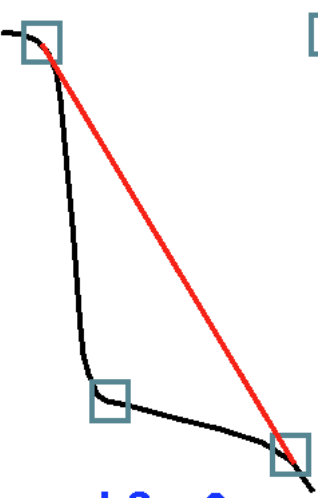

LS $<0$

RS $<0$

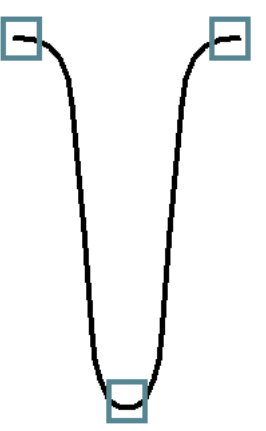

LS $=1$

RS $=1$

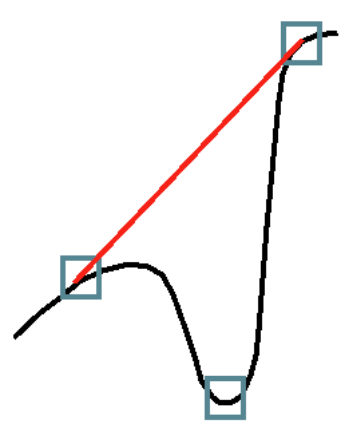

$0<L S<1$

RS $>1$

rc = Right Continuum

Ic = Left Continuum

Left Shoulderness:

Right Shoulderness:

$\mathrm{bb}=$ Band Bottom

Figure 10. Definition of spectral "shoulderness." 


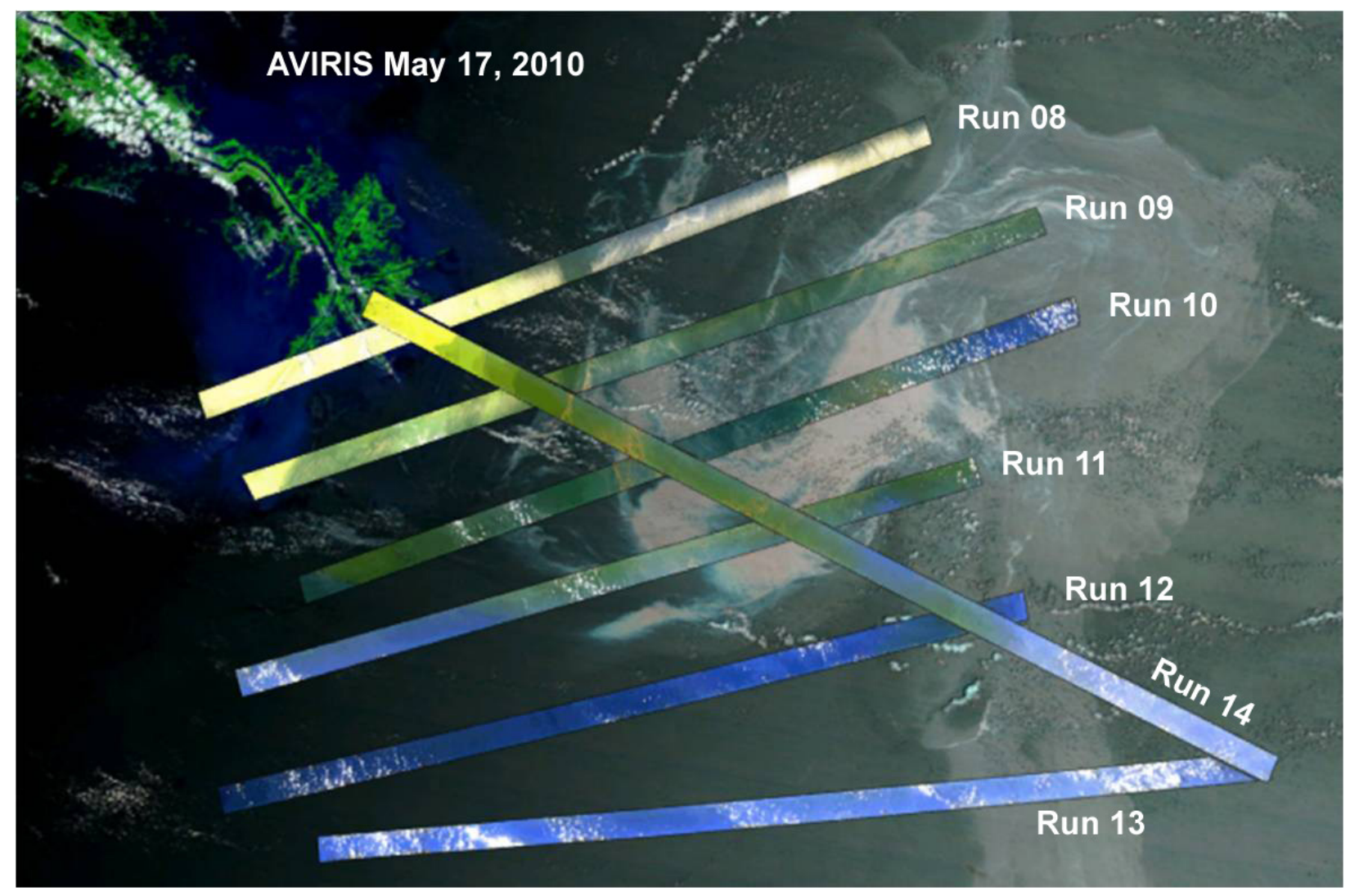

Figure 11. AVIRIS flight lines for May 17, 2010, over the Deepwater Horizon, Gulf of Mexico, oil spill. The background image is from MODIS Terra acquired the same day (see figure 16a for a registered image of the MODIS data). At upper left is a portion of the "bird's foot" region of the Mississippi River delta in Louisiana. North is up, and the width of the AVIRIS flight lines is about 5.5 kilometers. 


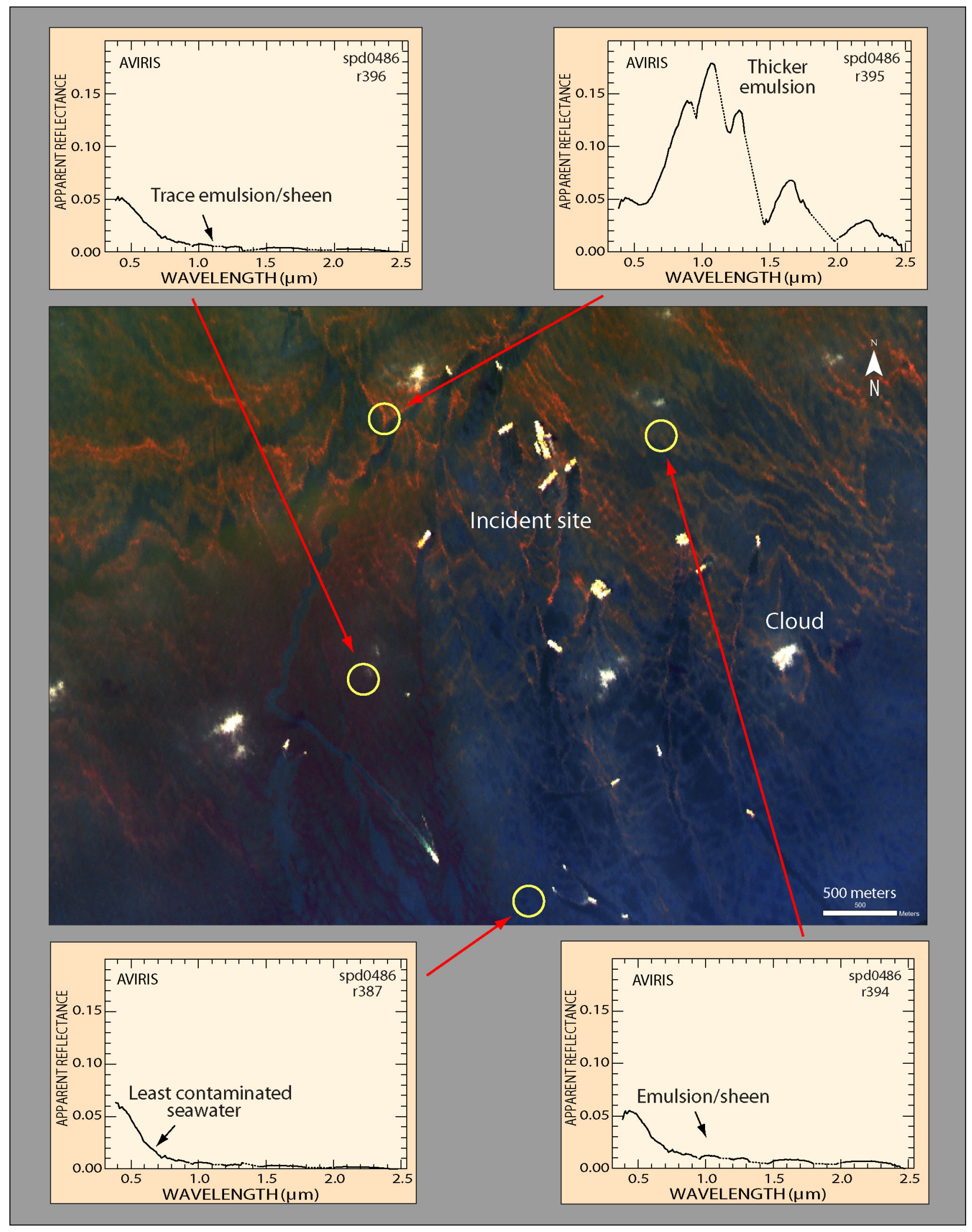

Figure 12. AVIRIS visible-color composite image and example spectra. 


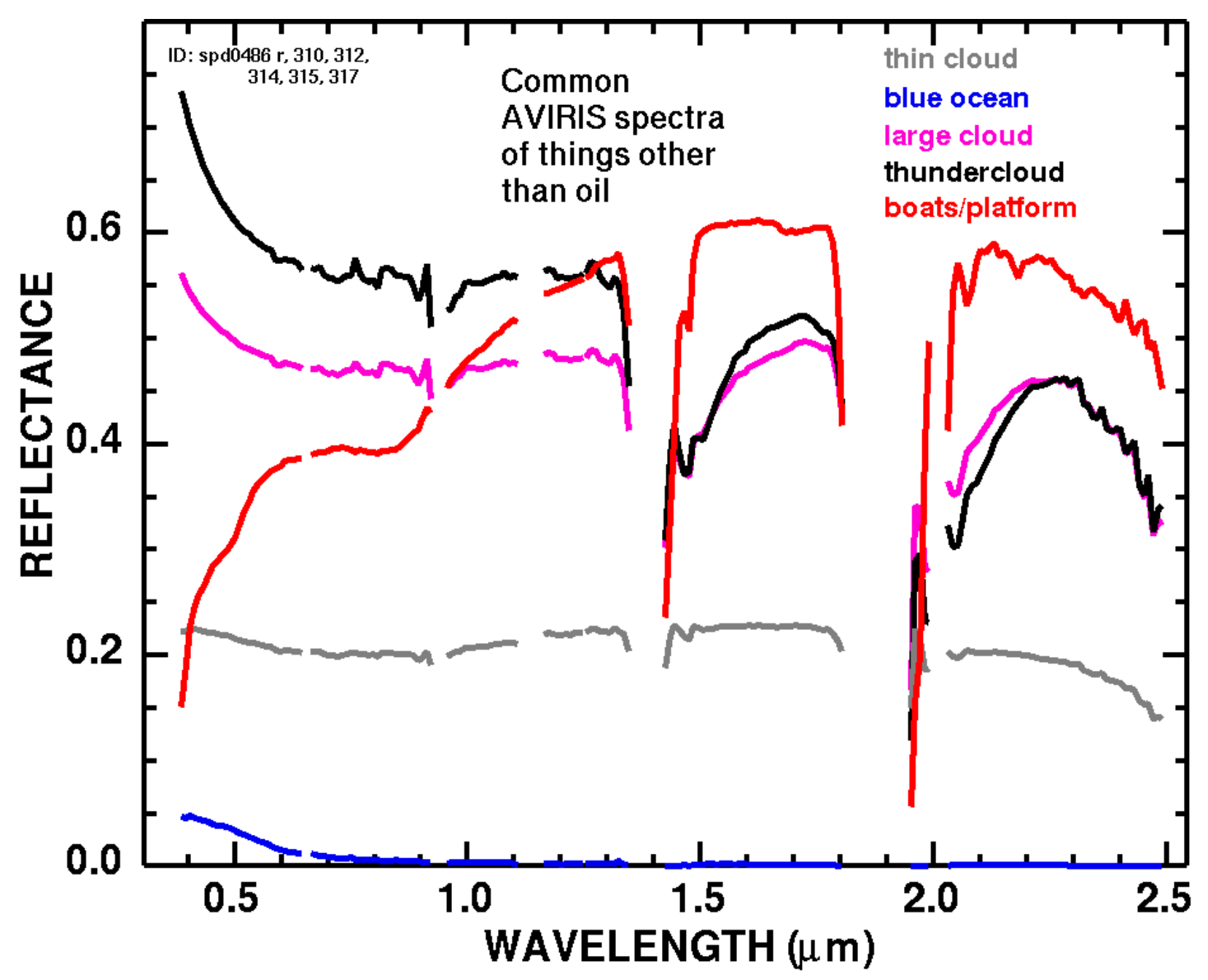

Figure 13a. AVIRIS spectra from the May 17, 2010, flight of pixels containing no oil. Gaps in the spectra are locations where the terrestrial atmosphere absorbs too much light for analysis of the surface reflectance. 


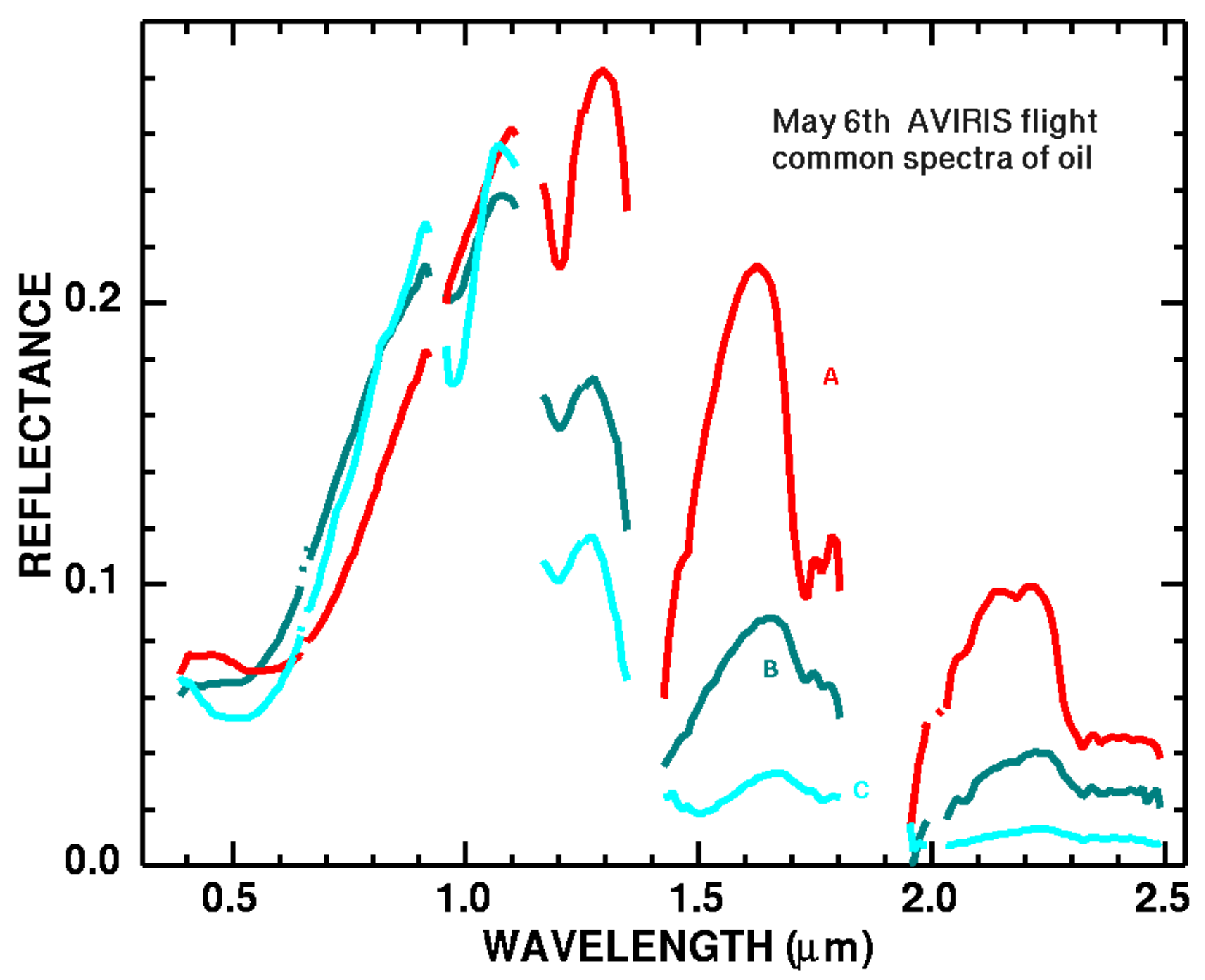

Figure 13b. AVIRIS spectra from pixels containing (A) high, (B) medium, and (C) low quantities of oil. Gaps in the spectra are locations where the terrestrial atmosphere absorbs too much light for analysis of the surface reflectance. 


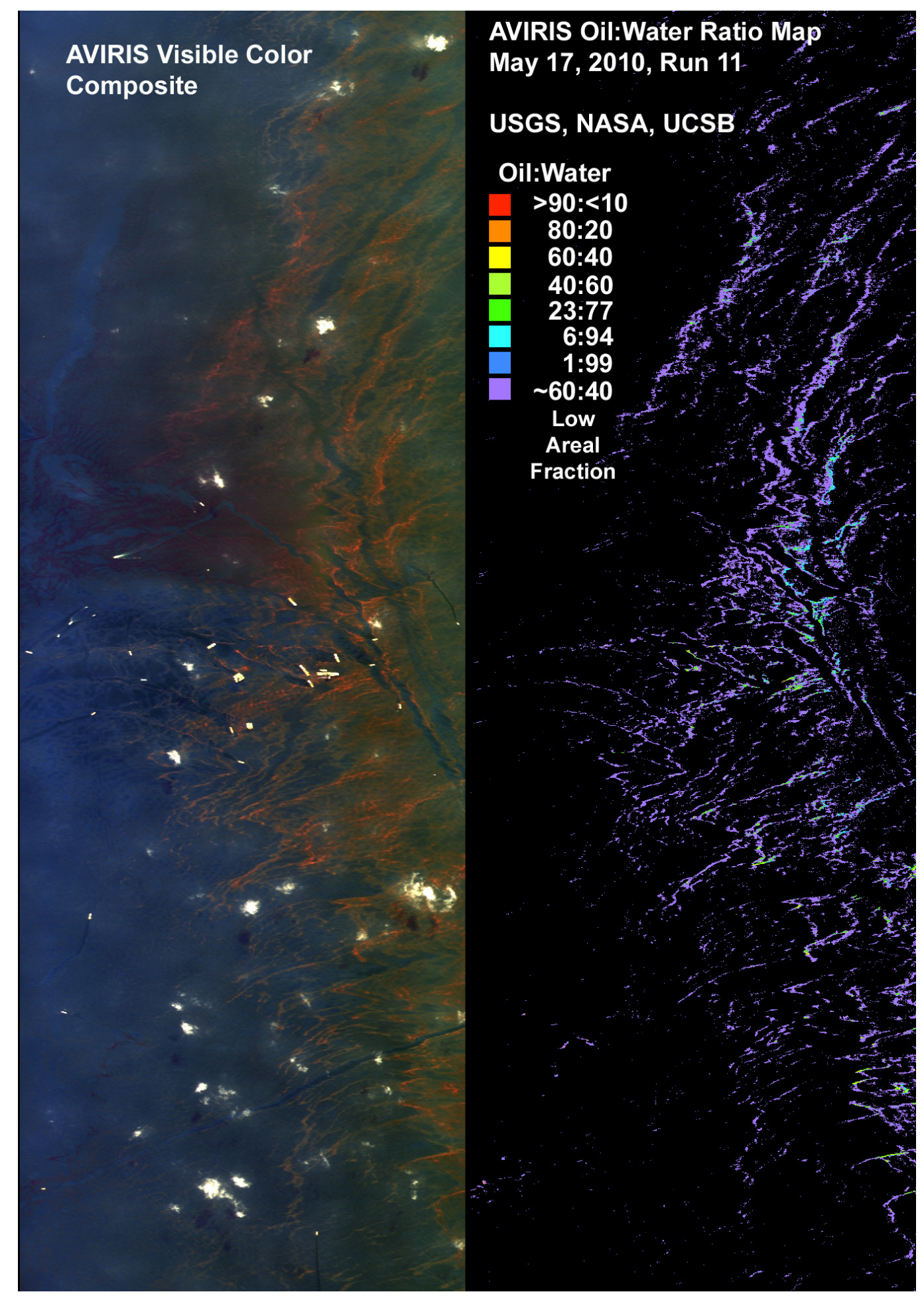

Figure 14a. Mapping results for oil-to-water ratio over the incident site for AVIRIS run 11, May 17, 2010. The width of the scene is about 5.5 kilometers and north is at about the 4 o'clock position. Black areas on the right panel are where no thick oil was detected. The left-to-right variations in apparent oil is not a viewing geometry effect; the image straddles the edge of where more oil is located on the ocean surface. 


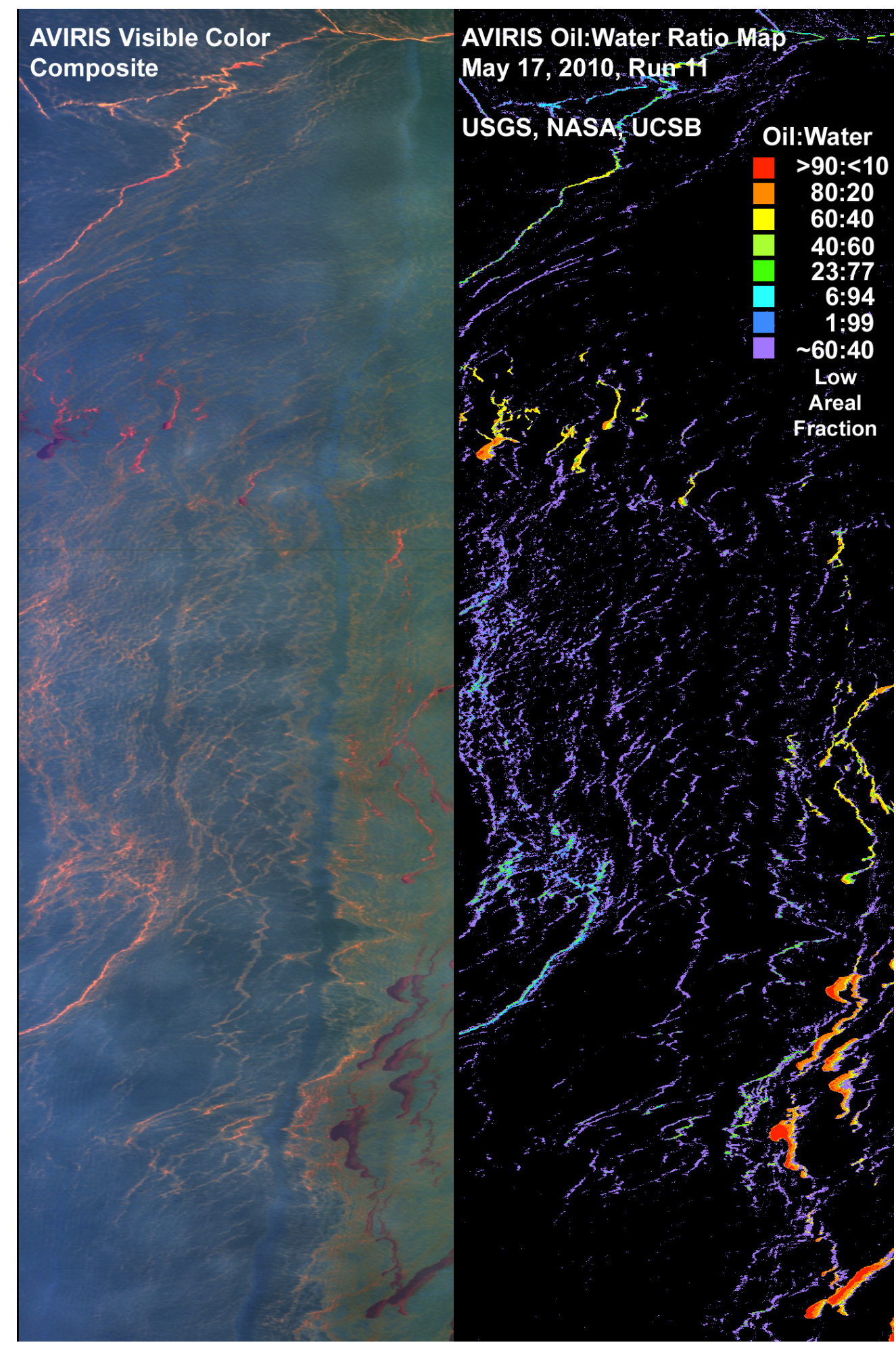

Figure 14b. Mapping results for oil-to-water ratio for a portion of AVIRIS run 11. The width of the scene is about 5.5 kilometers and north is at about the 4 o'clock position. Black areas on the right panel are where no thick oil was detected. The center of this image is about 12 kilometers west-southwest of the incident site. 

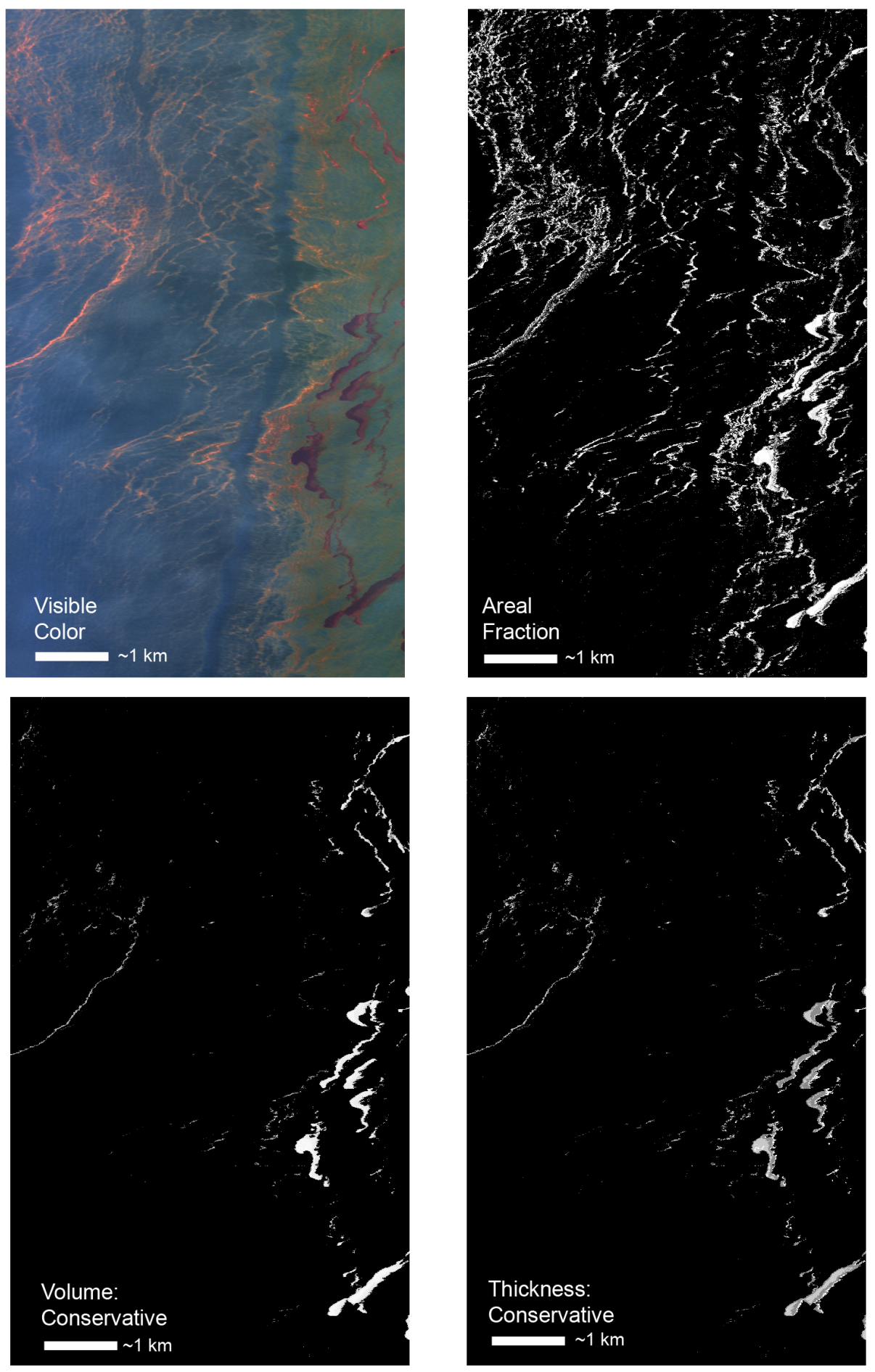

Figure 15a. Mapping results for portions of AVIRIS run 11 for sub-pixel areal fraction ( 0 to 1.0 , using a cumulative histogram stretch), volume (0 to 81 liters per pixel, cumulative histogram stretch), thickness ( 0 to 2 millimeters, linear stretch). North is at about the 4 o'clock position. 

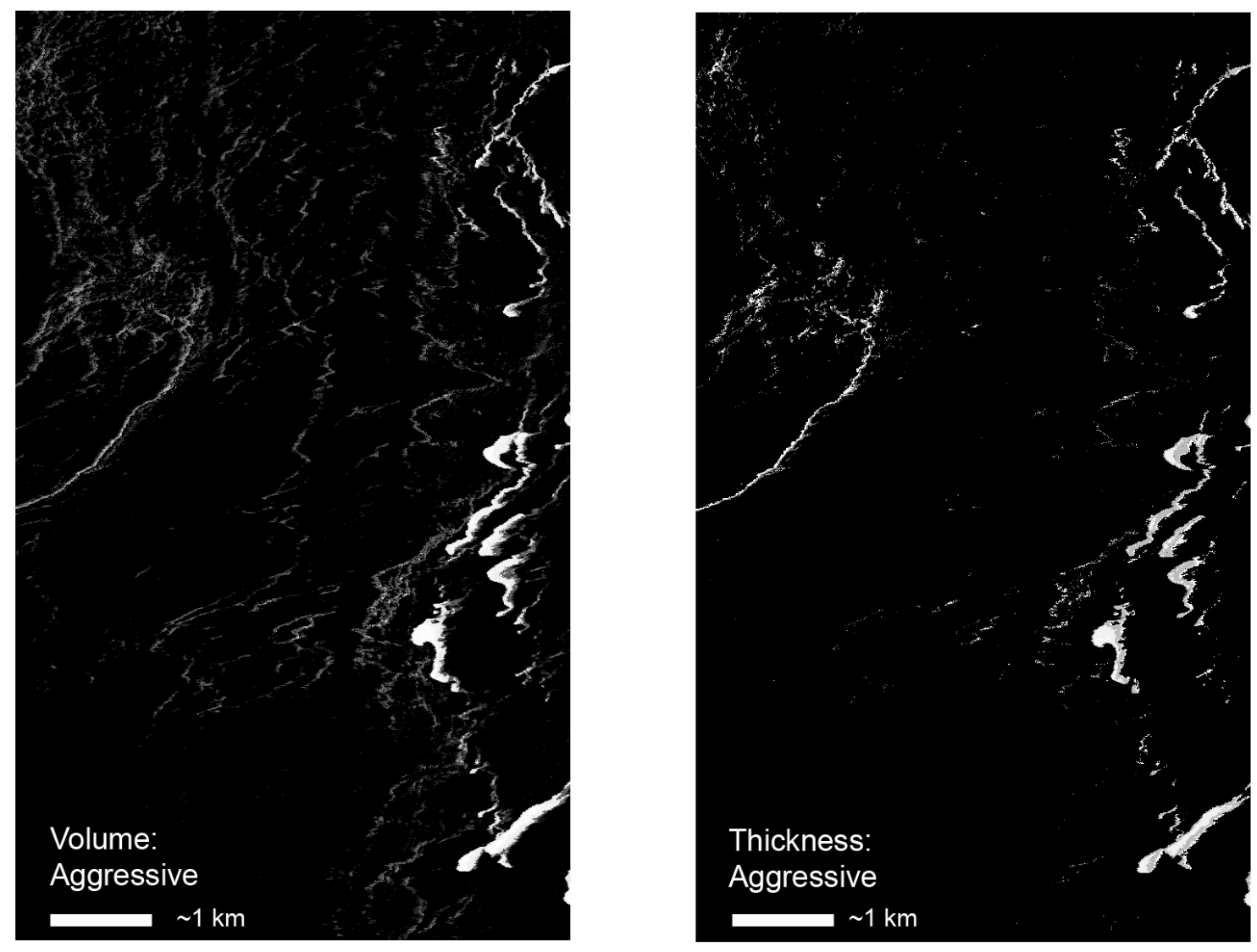

Figure 15b. Mapping results for portions of AVIRIS Run 11 for volume ( 0 to 131 liters per pixel, cumulative histogram stretch), and thickness (0 to 2 millimeters, linear stretch). North is at about the 4 o'clock position. 


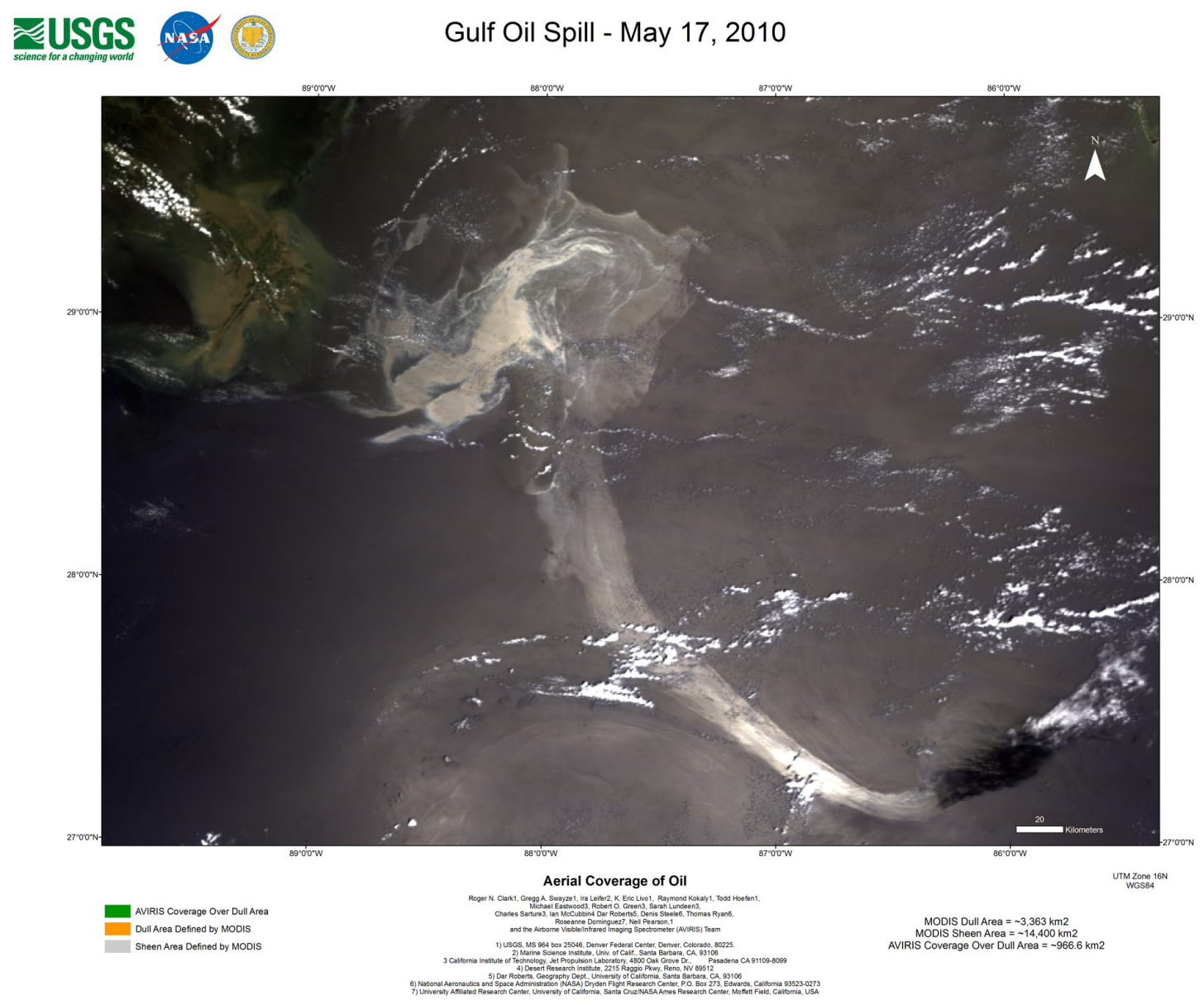

Figure 16a. Image of the spectral response from the oil spill area on May 17, 2010, from MODIS on the Terra Satellite. Lighter gray areas are interpreted to be sun glint reflecting off of the oil spill. See separate high-resolution jpeg file. 


\section{ZUSGS Gulf Oil Spill - May 17, 2010}

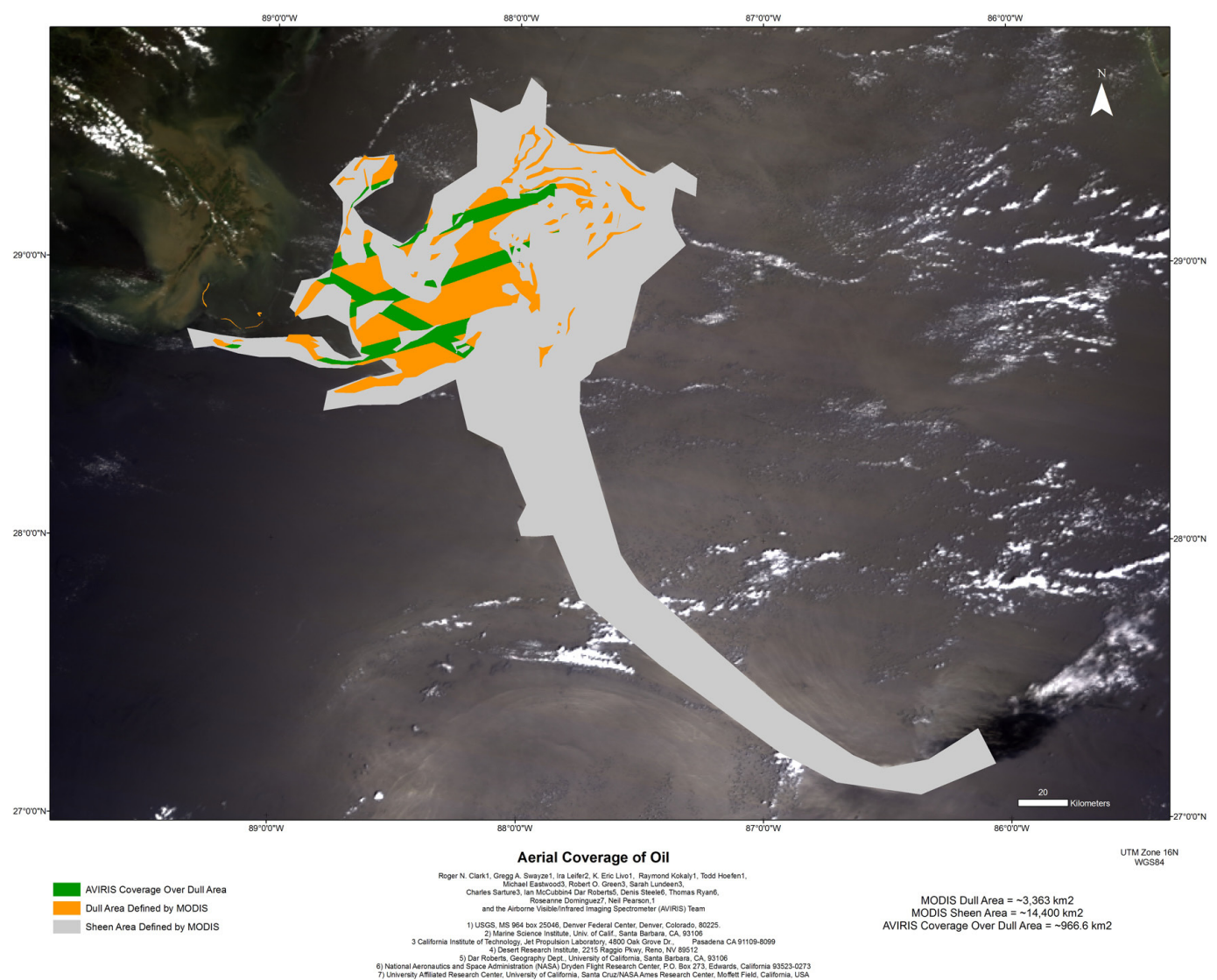

Figure 16b. MODIS image with zones overlain to indicate regions of oil. From overlap with the AVIRIS analysis, the MODIS imagery shows locations of both high and low oil abundance, as discussed in the text. Excluding the tail and the light gray zone $\left(14,400 \mathrm{~km}^{2}\right)$, analysis of the MODIS data indicates an area of $3,363 \mathrm{~km}^{2}$ of more abundant oil (orange + green). The AVIRIS data that overlap the MODIS orange regions are shown as green, and they cover a combined $966.6 \mathrm{~km}^{2}$. See separate highresolution jpeg file. 


\section{Eulf Oil Spill - May 17, 2010}

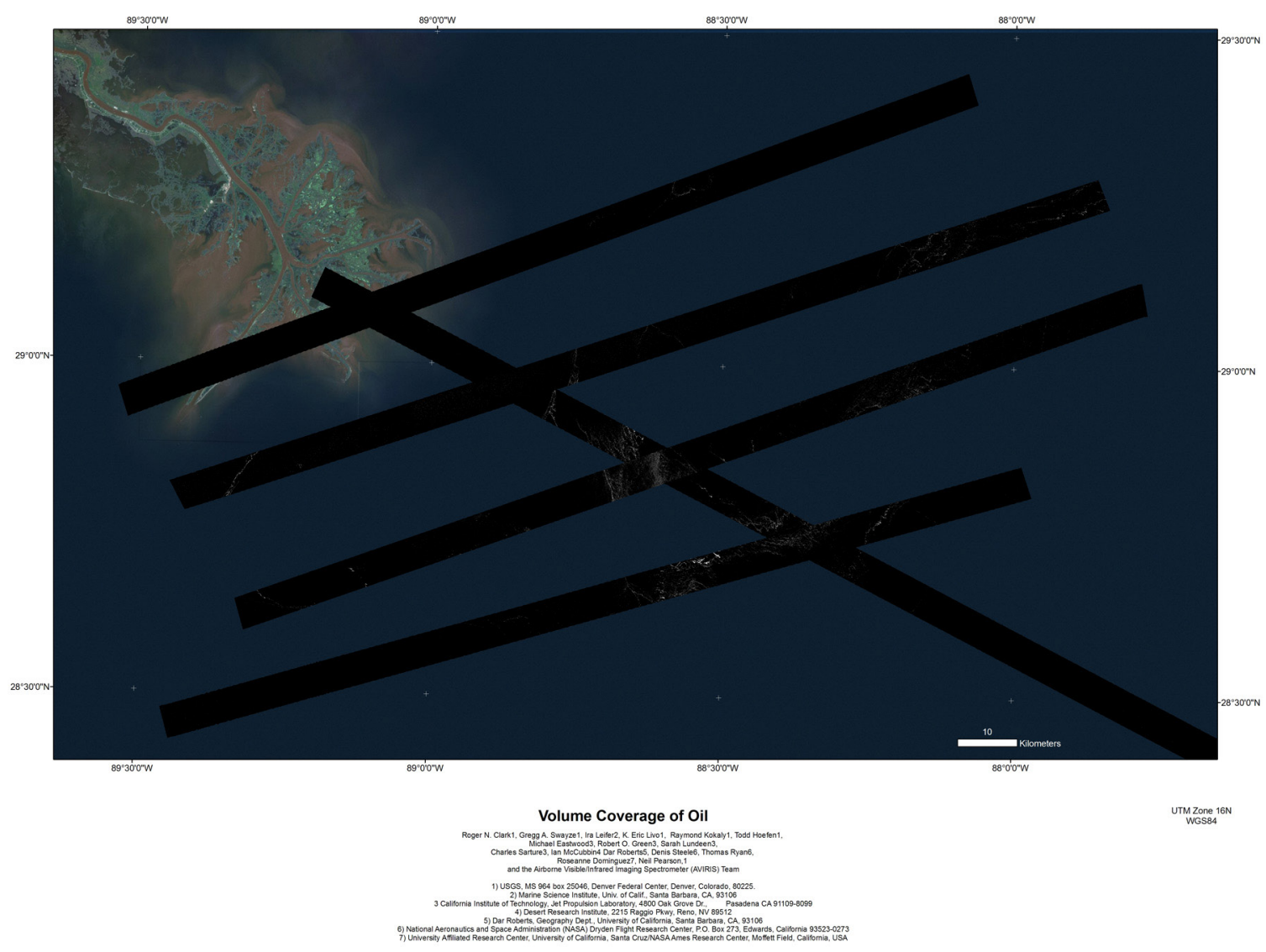

Figure 16c. Mosaic of AVIRIS lines $08,09,10,11$, and 14 showing oil volume (aggressive estimate). See separate high-resolution jpeg file.

A separate geotiff file is also provided. In the geotiff file, each data number (DN) is one liter. If a pixel has a value of 32 , there are 32 liters in that pixel. A value of zero is zero oil volume for that pixel in the flight line. Values of -1 are outside the AVIRIS flight lines. 